Pecunia Monográfico 2013-2014 (Número especial), pp. 213-238

\title{
EL SECTOR FINANCIERO EN LA PROVINCIA DE LEÓN (1986-2012)
}

\author{
José Miguel Fernández Fernández \\ Catedrático de Economía Financiera y Contabilidad \\ Departamento de Dirección y Economía de la Empresa \\ Universidad de León \\ e-mail: jose-miguel.fernandez@unileon.es
}

1. Introducción - 2. Estructura del sector financiero en León: 2.1. Número de oficinas, 2.2. Depósitos, 2.3. Créditos, 2.4. Hipotecas, 2.5. Indicadores: 2.5.1. Grado de bancarización, 2.5.2. Tamaño medio de las oficinas, 2.5.3. Productividad del personal - 3. A modo de conclusión: fortalezas, debilidades y estrategias de desarrollo - Referencias

\section{Introduc ción}

El presente artículo pretende analizar el sector financiero en León desde la entrada de España en la Comunidad Económica Europea hasta el año 2012. Se trata de detectar las fortalezas que presenta y las debilidades que persisten para diseñar estrategias de desarrollo que le permitan cumplir adecuadamente con la función que deben desarrollar en la economía de la provincia.

Para ello, se utilizarán las estadísticas de diversas variables que definen la actuación del sistema financiero, tales como créditos concedidos, depósitos captados, hipotecas constituidas, etc., disponibles en el Sistema de Información Estadística (SIE) de la Comunidad Autónoma de Castilla y León y en el Instituto Nacional de Estadística de España (INE). Asimismo, se recurrirá a los informes anuales elaborados por la Asociación Española de la Banca, la Confederación Española de Cajas de Ahorros y la Unión Nacional de Cooperativas de Crédito.

Con la finalidad de comprender adecuadamente la evolución y estructura del sector financiero en León durante ese periodo, se realizarán comparaciones de carácter regional con la Comunidad
Autónoma de Castilla y León, y de carácter nacional con el total de España.

Dado el impacto que la crisis financiera actual está produciendo en la situación económica del país y en particular en las entidades que componen el sistema financiero, cabe pensar que el inicio de la crisis en el año 2007 marcará un punto de inflexión en la trayectoria seguida por las variables más relevantes. Esta será la hipótesis de partida que trataremos de contrastar con los datos a lo largo del artículo.

Sin embargo, antes de introducirnos en el núcleo del análisis, resulta imprescindible comentar de manera resumida la situación actual a $31 / 12 / 2012^{1}$ del sector financiero español y su evolución reciente. Esta situación ha venido fuertemente condicionada por la crisis financiera que comenzó en el año 2007 y que ha supuesto

1 Resulta imprescindible fijar el término del periodo estudiado dada la agitada transformación que se está produciendo casi a diario en los procesos de reordenación de las entidades financieras. Las exigencias de la Unión Europea para el saneamiento del sistema financiero, conllevan cambios de rumbo a veces radicales en estos procesos de reestructuración, lo que puede invalidar el estudio si no se especifica claramente el periodo que comprende. 
una profunda reordenación del sistema bancario español, en particular del subsector de las cajas de ahorros y de las cooperativas de crédito. Este proceso de reforma del sistema bancario ha tenido sus manifestaciones más abundantes a partir del año 2010, año en el que se comenzaron a multiplicar las fusiones, absorciones, adquisiciones y particularmente la formación de sistemas institucionales de protección (SIP) surgidos al amparo de la Directiva 2006/48/CE, de 14 de junio, de acceso a la actividad de las entidades de crédito, y trasladados a la legislación española en el año 2008. Aunque los SIP estaban concebidos como un instrumento para fortalecer la solvencia y la estabilidad financiera de las entidades integrantes y mejorar su eficiencia, la realidad ha venido a desmentir a menudo esta pretensión, produciéndose fracasos estrepitosos que han requerido el rescate con fondos públicos.

\section{Tabla 1}

\section{Estructura del sector bancario español}

\begin{tabular}{|c|c|c|c|c|c|c|c|c|c|c|c|c|}
\hline & \multicolumn{2}{|c|}{2006} & \multicolumn{2}{|c|}{2007} & \multicolumn{2}{|c|}{2008} & \multicolumn{2}{|c|}{2009} & \multicolumn{2}{|c|}{2010} & \multicolumn{2}{|c|}{2011} \\
\hline $\begin{array}{l}\text { CRÉDITO } \\
\text { REGISTRADAS } \\
\text { EN ESPAÑA (a) }\end{array}$ & \multicolumn{2}{|c|}{355} & \multicolumn{2}{|c|}{358} & \multicolumn{2}{|c|}{362} & \multicolumn{2}{|c|}{352} & \multicolumn{2}{|c|}{337} & \multicolumn{2}{|c|}{306} \\
\hline $\begin{array}{l}\text { Entidades de } \\
\text { depósito }\end{array}$ & 276 & $77,75 \%$ & 282 & $78,77 \%$ & 286 & $79,01 \%$ & 280 & $79,55 \%$ & 276 & $81,90 \%$ & 247 & $80,72 \%$ \\
\hline Bancos & 144 & $52,17 \%$ & 151 & $53,55 \%$ & 159 & $55,59 \%$ & 153 & $54,64 \%$ & 160 & $57,97 \%$ & 165 & $66,80 \%$ \\
\hline Nacionales & 54 & $37,50 \%$ & 53 & $35,10 \%$ & 71 & $44,65 \%$ & 65 & $42,48 \%$ & 72 & $45,00 \%$ & 79 & $47,88 \%$ \\
\hline Extranjeros & 90 & $62,50 \%$ & 98 & $64,90 \%$ & 88 & $55,35 \%$ & 88 & $57,52 \%$ & 88 & $55,00 \%$ & 86 & $52,12 \%$ \\
\hline $\begin{array}{l}\text { Cajas de } \\
\text { ahorros }^{2}\end{array}$ & 47 & $17,03 \%$ & 46 & $16,31 \%$ & 46 & $16,08 \%$ & 46 & $16,43 \%$ & 36 & $13,04 \%$ & 6 & $2,43 \%$ \\
\hline $\begin{array}{l}\text { Cooperativas de } \\
\text { crédito }\end{array}$ & 85 & $30,80 \%$ & 85 & $30,14 \%$ & 81 & $28,32 \%$ & 81 & $28,93 \%$ & 80 & $28,99 \%$ & 76 & $30,77 \%$ \\
\hline $\begin{array}{l}\text { Establecimientos } \\
\text { financieros de } \\
\text { crédito }\end{array}$ & 79 & $22,25 \%$ & 76 & $21,23 \%$ & 75 & $20,72 \%$ & 70 & $19,89 \%$ & 59 & $17,51 \%$ & 59 & $19,28 \%$ \\
\hline
\end{tabular}

(a) El número de EC registradas incluye el ICO, que se incorpora en la categoría de banca nacional.

Fuente: Banco de España. Datos disponibles a 31 de diciembre de 2011.

Del análisis de la tabla anterior se deduce el fuerte descenso de un $16 \%$ experimentado por las entidades de créditos con actividad financiera directa a partir del año 2008, ocasionado fundamentalmente por la reordenación del subsector de cajas de ahorros y de las cooperativas de créditos, en menor medida. En cambio el subsector de la Banca privada ha crecido en los dos últimos años debido a los bancos creados al objeto de recibir el negocio financiero de las cajas de ahorros que han dejado de realizar su actividad financiera de manera

\footnotetext{
2 Solamente se incluyen las cajas de ahorros con actividad financiera directa. A 31 de diciembre de 2011 había 29 cajas de ahorros sin actividad financiera directa, participantes en sistemas institucionales de protección (SIP).
} 
directa $^{3}$. Como resultado del proceso se puede concluir que la crisis financiera ha ocasionado la práctica desaparición de las cajas de ahorros, por lo que el estudio que se realiza en este artículo tiene validez en el contexto del periodo analizado, pero carecerá de relevancia de cara a su proyección hacia el futuro.

En algunas parcelas del estudio, en particular respecto al número de empleados de las cajas de ahorros, no ha sido posible obtener datos segmentados respecto a las entidades que componen el sector financiero leonés, ya que las estadísticas disponibles solamente hacen referencia a las entidades de la Comunidad Autónoma o a todo el Estado Español.

\section{Estructura del sector financiero en León}

En primer lugar nos centraremos en el estudio de cuatro variables clave que permiten conocer la evolución y estructura del sector financiero en León: el número de oficinas, el volumen de depósitos obtenidos, el importe de los créditos concedidos y el número y valor de las hipotecas constituidas.

\subsection{Número de ofic inas}

El número total de oficinas de entidades de depósito ha experimentado un importante crecimiento en la provincia leonesa desde el año 1993 (447 oficinas), primer año del que se dispone de datos fiables, hasta el año 2011
(511 oficinas), lo que supone un incremento del $14,3 \%$, superior en todo caso al que experimenta el número total de oficinas en la Comunidad Autónoma $(-0,5 \%)$ y en España $(7,22 \%)$.

Entrando en el análisis estructural de las entidades de depósito y observando su evolución histórica se puede apreciar cómo hasta el año 2002, el número de oficinas de la banca privada se situaba por encima del relativo a las cajas de ahorros, invirtiéndose la situación a partir de ese momento (Tabla 2 y Gráfico 1). Mientras en el año 1993 existían 270 oficinas de la banca privada y solamente 177 de cajas de ahorros, en 2011 la situación se había invertido descendiendo las primeras a 211 (descenso de un 22\% -de un 29,5\% en Castilla y León-) y ascendiendo las segundas a 270 (lo que equivale a un aumento del $52,5 \%$, -un $14,8 \%$ en la Comunidad Autónoma-). En Castilla y León esa circunstancia se produce cinco años antes, concretamente en el ejercicio 1997 y en España en 1999. Se confirma, pues, la mayor importancia que fueron cobrando las cajas de ahorros españolas con respecto a los restantes agentes otorgantes de crédito, como consecuencia de los procesos de expansión llevados a cabo en los últimos años. En efecto, las cajas de ahorros dejan de estar vinculados exclusivamente a un ámbito territorial determinado, para iniciar procesos de expansión en otras regiones mediante la apertura de sucursales.

Tabla 2

Número de oficinas de entidades de depósito en León

\begin{tabular}{|l|r|r|r|r|r|r|r|r|r|}
\hline & 1993 & 1996 & 1998 & $\mathbf{2 0 0 0}$ & $\mathbf{2 0 0 2}$ & $\mathbf{2 0 0 4}$ & $\mathbf{2 0 0 6}$ & $\mathbf{2 0 0 8}$ & $\mathbf{2 0 1 1}$ \\
\hline Bancos & 270 & 271 & 278 & 252 & 216 & 219 & 223 & 226 & 210 \\
\hline Cajas de Ahorros & 177 & 180 & 202 & 222 & 223 & 228 & 258 & 292 & 270 \\
\hline Cooperativas de Crédito & 0 & 4 & 7 & 16 & 19 & 19 & 26 & 31 & 31 \\
\hline Total Entidades de Depósito & 447 & $\mathbf{4 5 5}$ & $\mathbf{4 8 7}$ & $\mathbf{4 9 0}$ & $\mathbf{4 5 8}$ & $\mathbf{4 6 6}$ & $\mathbf{5 0 7}$ & $\mathbf{5 4 9}$ & $\mathbf{5 1 1}$ \\
\hline
\end{tabular}

Fuente: Dirección General de Estadística. Junta de Castilla y León.

\footnotetext{
3 Al inicio de 2012, y como resultado de los procesos mencionados, solo tres cajas de ahorros continúan con su actividad financiera como tales: la CECA, la CAMP de Ontinyent y la Caixa d'Estalvis de Pollença.
} 
La situación descrita puede comprenderse fácilmente si se analiza el Gráfico 2 donde figura la cuota de penetración -porcentaje de cada entidad, respecto a las oficinas totales de las entidades de depósito- de bancos privados, cajas de ahorros y cooperativas de crédito en León en los años 1993 y 2011. Mientras en el año 1993, los bancos poseían el $60 \%$ de las oficinas bancarias totales, en el año 2011 quedaban reducidas al $41 \%$ del total (32\% del total en Castilla y León y $36 \%$ en España); por su parte, las oficinas de cajas de ahorros pasan de suponer el $40 \%$ al $54 \%$ (con porcentajes similares en Castilla y León y España).

\section{Gráfico 1}

Evolución del número de oficinas de entidades de depósito en León. Años 1993/2011

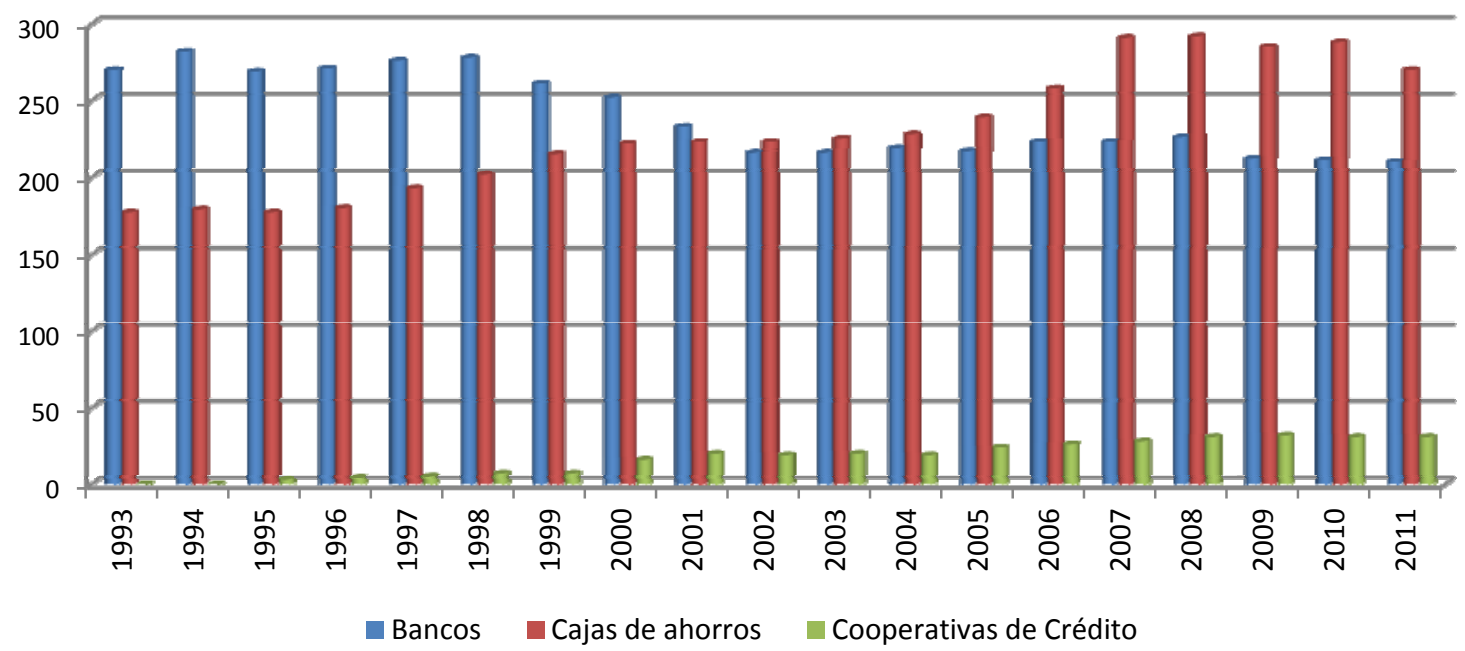

Fuente: Elaboración propia a partir de los datos de la Dirección General de Estadística de la Junta de Castilla y León.

Hay que destacar, además, que hasta el año 1995 no existía ninguna oficina de cooperativas de crédito en la provincia, produciéndose a partir de ese momento un aumento paulatino de las mismas como puede observarse en el Gráfico 1 y llegando a suponer en el año 2011 el $6 \%$ del total de oficinas de entidades de depósito leonesas $-16 \%$ en Castilla y León y $12 \%$ a nivel nacional.

En resumen, del análisis de la estructura del sector de entidades de depósito leonesas se deduce un mayor crecimiento en León del número de oficinas que en la Comunidad Autónoma Castellano-Leonesa y que en España, propiciada sobre todo por el subsector de cajas de ahorros y cooperativas de crédito y a costa del subsector de la banca privada que pierde peso relativo en su cuota de penetración año tras año.
También resulta destacable el hecho del paulatino descenso de oficinas de bancos y cajas de ahorros que se ha producido desde el año 2008 como consecuencia de la crisis del sector financiero, más acusado en las segundas como se observa con claridad en el Gráfico 1 y ello a pesar de que en las estadísticas oficiales continúan considerándose como cajas de ahorros entidades que se han transformado en ban$\cos ^{4}$. La crisis ha puesto de manifiesto el exceso de capacidad instalado, especialmente en el subsector de las cajas de ahorros, y ha exigido un ajuste paulatino en el número de oficinas para combatir los problemas detectados.

4 De hecho, cuando se escriben estas líneas, febrero de 2013, la práctica totalidad de las oficinas de cajas de ahorros que operan en la provincia pertenecen a bancos creados a partir de dichas cajas. 


\section{Gráfico 2}

Distribución porcentual del número de oficinas de entidades de depósito en León. Años 1993 y 2011
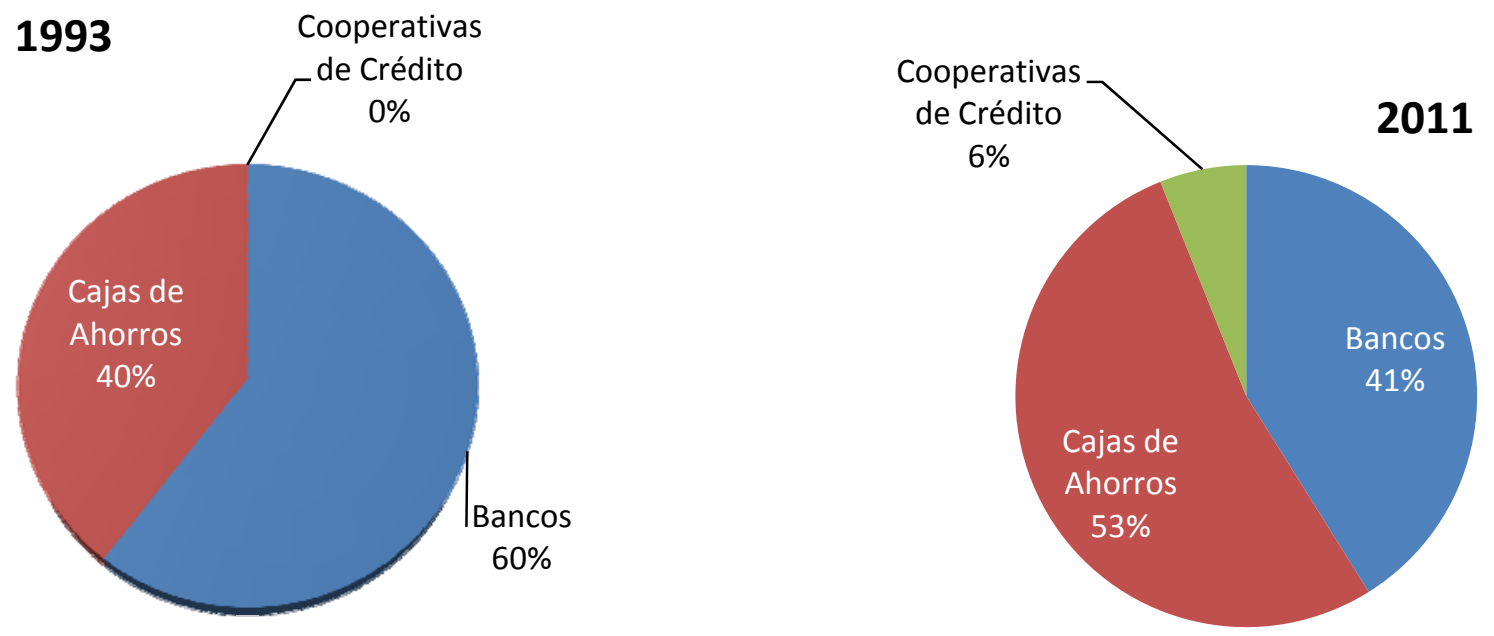

Fuente: Elaboración propia a partir de los datos de la Dirección General de Estadística de la Junta de Castilla y León.

\subsection{Depósitos}

En la Tabla 3 y en el Gráfico 3 figura recogida la evolución experimentada por los depósitos de las entidades de crédito leonesas en el periodo 1986-2011. De su observación se deduce el fuerte crecimiento de los depósitos durante el periodo considerado con un incremento del $441 \%$, si bien se observan comportamientos diversos dependiendo del tipo de entidades de depósito de que se trate.

\section{Tabla 3}

Depósitos de las entidades de crédito leonesas. Periodo 1986-2011 (miles de euros)

\begin{tabular}{|l|c|c|c|c|c|c|c|c|}
\hline & 1986 & 1990 & 1994 & 1998 & 2002 & 2006 & 2010 & 2011 \\
\hline $\begin{array}{l}\text { BANCA } \\
\text { PRIVADA }\end{array}$ & $1.119 .123,50$ & $1.601 .852,25$ & $1.925 .000,00$ & $1.884 .990,25$ & $2.404 .750,00$ & $2.732 .655,25$ & $4.439 .651,25$ & $4.794 .106,00$ \\
\hline $\begin{array}{l}\text { CAJAS DE } \\
\text { AHORRO }\end{array}$ & $715.969,00$ & $1.168 .668,00$ & $2.178 .006,25$ & $3.360 .452,50$ & $5.086 .750,00$ & $5.920 .265,50$ & $6.791 .229,00$ & $8.462 .317,00$ \\
\hline $\begin{array}{l}\text { COOPERATIVAS } \\
\text { DE CRÉDITO }\end{array}$ & $74.760,00$ & $111.187,50$ & 0,00 & $9.904,75$ & $78.500,00$ & $182.307,00$ & $345.658,00$ & $361.162,00$ \\
\hline
\end{tabular}

Fuente: Dirección General de Estadística. Junta de Castilla y León. 


\section{Gráfico 3}

Evolución de los depósitos de las entidades de crédito. Periodo 1986-2011

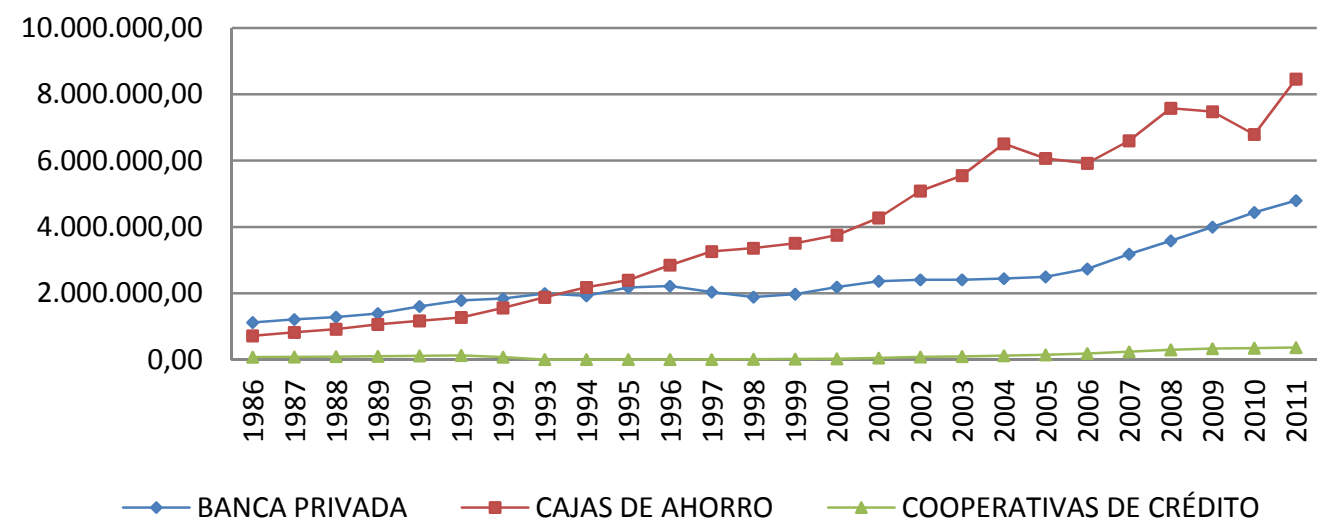

Fuente: Elaboración propia a partir de los datos de la Dirección General de Estadística de la Junta de Castilla y León.

Mientras la banca privada muestra un crecimiento sostenido de los depósitos a un ritmo anual en torno al $15 \%$, las cajas de ahorros, por su parte, lo hacen a tasas muy superiores (25\%), observándose una situación similar en la Comunidad Autónoma de Castilla y León. Este hecho, explica que la tasa de penetración de las cajas haya ganado peso a costa de la correspondiente a los bancos; así de una situación inicial en 1986 en la que la cuota de participación de los bancos en los depósitos captados de los clientes suponía el $59 \%$ del total -frente al $37 \%$ de las cajas y el $4 \%$ de las cooperativas de crédito-, se haya pasado a la situación inversa en la que se constata la supremacía de las cajas de ahorros en el ámbito de los depósitos captados -62\%-, sobre los bancos privados $-35 \%-y$ cooperativas de crédito $-3 \%$ - (Gráfico 4). El punto de inflexión en la tendencia descrita se produjo en el año 1994, resaltando a partir de esa fecha el distanciamiento entre ambas categorías de entidades y llegándose a una situación en el año 2011 en la que los depósitos captados por los bancos apenas suponen el $56,6 \%$ de los captados por las cajas.

\section{Gráfico 4}

Cuota de participación en los depósitos captados en León por las distintas entidades. Año 1986 y 2011
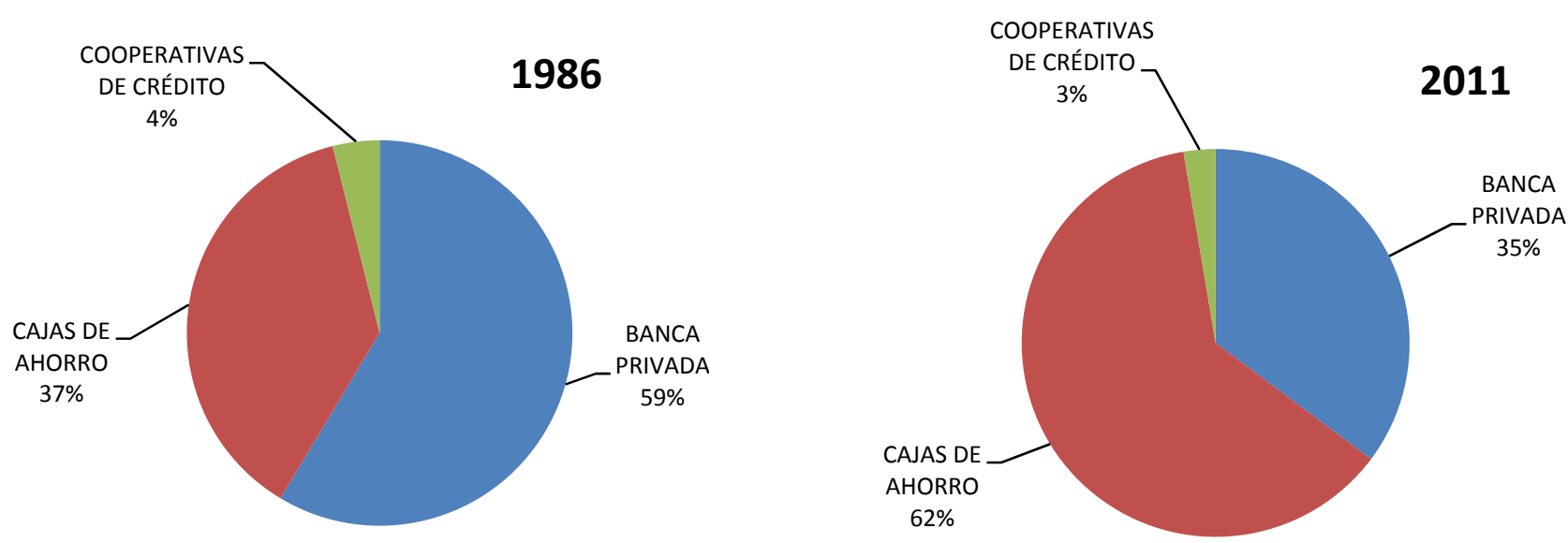

Fuente: Elaboración propia a partir de los datos de la Dirección General de Estadística de la Junta de Castilla y León. 
Por su parte, la tasa de penetración de las cooperativas de crédito en cuanto a la captación de depósitos se refiere, se mantiene en cifras poco significativas (en torno al 3\% del total), en cualquier caso inferiores a las que presentaban respecto al número de oficinas $(5 \%)$.

En Castilla y León se observa un comportamiento similar, si bien el punto de inflexión en el comportamiento anteriormente descrito se produjo antes (año 1992) y la participación de las cooperativas de crédito en la captación de depósitos es mayor (9\%). Por su parte, en el año 2011 los depósitos de las cajas suponían el $58 \%$ del total, mientras que los de la banca privada se limitaban al 33\%.

En el ámbito español cabe destacar que la pérdida de participación de la banca privada en el total de depósitos captados es inferior a la comentada para la provincia y la Comunidad Autónoma, situándose en el año 2011 en el 47\% frente al $46 \%$ de las cajas.

En todos los casos se constata la relevancia de este grupo financiero en la captación de recursos financieros en forma de depósitos en cualquiera de los ámbitos geográficos considerados, poniendo de manifiesto la importancia que tiene la cercanía a los clientes, derivada del crecimiento en el número de oficinas, en el proceso de captación del ahorro de los ciudadanos.

En cuanto a los sectores de los que proceden los depósitos captados, en su inmensa mayoría -en torno al $96 \%$ - proceden, como cabía esperar, del sector privado, frente a la escasa relevancia de los depósitos de las Administraciones Públicas a lo largo del periodo considerado. En Castilla y León y nuestro país se observan situaciones similares, si bien durante los últimos años ha aumentado la participación relativa de los depósitos de Administraciones Públicas en el total (6\% en España). No obstante, esta participación es meramente residual y está ocasionada más por la necesidad que tienen las Administraciones Públicas de mantener una cierta liquidez para asegurar su funcionamiento cotidiano, que por el interés en rentabilizar sus fondos.

Descendiendo a analizar la estructura de los depósitos del sector privado en sus distintas versiones -depósitos a la vista, depósitos de ahorro y depósitos a plazo-, el Gráfico 5 muestra la evolución experimentada por cada categoría durante el periodo analizado, así como la importancia relativa de cada tipo.

\section{Gráfico 5}

\section{Evolución de los depósitos del sector privado leonés por categorías}

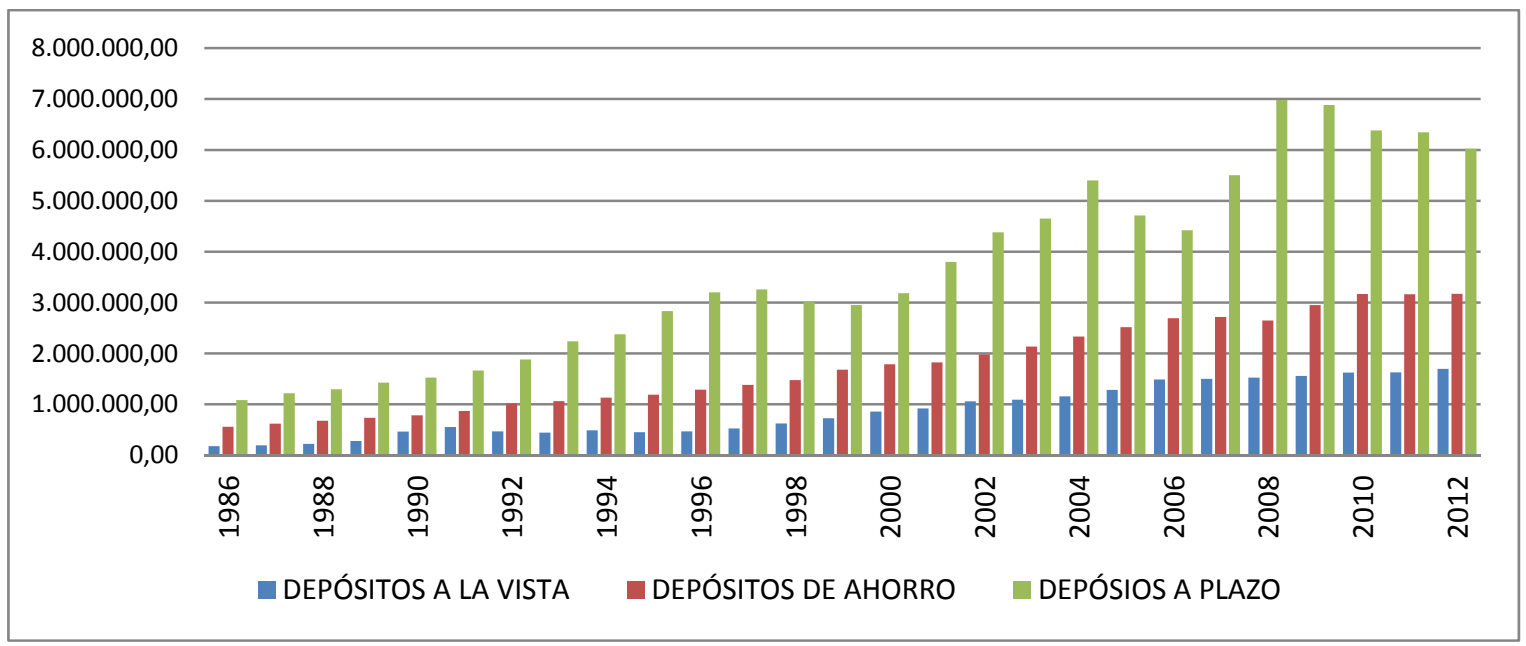

Fuente: Elaboración propia a partir de los datos de la Dirección General de Estadística de la Junta de Castilla y León. 
En primer lugar, podemos apreciar cómo en nuestra provincia los depósitos a plazo siguen una tendencia creciente y tienen una importancia ligeramente superior que en la esfera nacional, con una proporción del 55\% en 2012 (Gráfico 6). En la
Comunidad Autónoma y en el ámbito nacional, la participación es del $58 \%$, manteniéndose prácticamente constante a lo largo del periodo estudiado.

\section{Gráfico 6}

Distribución de los depósitos del sector privado leonés por categorías. Año 2012

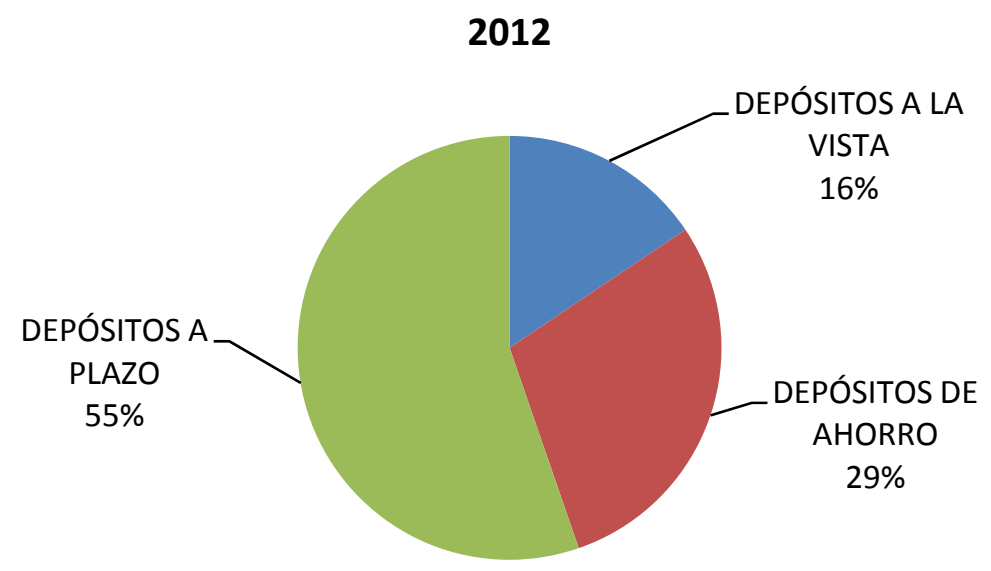

Fuente: Elaboración propia a partir de los datos de la Dirección General de Estadística de la Junta de Castilla y León.

Las diferencias, sin embargo, son más ostensibles en lo que se refiere a depósitos a la vista y depósitos de ahorro, destacando la escasa disposición a colocar los ahorros en depósitos a la vista por parte de los inversores de nuestra región, $16 \%$, frente al $14 \%$ de Castilla y León y el $24 \%$ de media nacional en dicho año, y la mayor propensión a acudir a los depósitos de ahorro $-29 \%$ frente al $19 \%$ en España-; ello es coherente con el peso de las cajas de ahorro en León, en cuanto entidades orientadas a un negocio bancario al por menor muy vinculado a una clientela de economías domésticas con pautas de ahorro bastante tradicionales.

Si analizamos la composición de los depósitos del sector privado por agentes, cabe destacar, tomando como referencia los datos del año 2011, la menor proporción de los depósitos a plazo en las Cajas de ahorro (54\%) frente a las cooperativas de crédito $(60 \%)$ y la banca privada (61\%) y la mayor de los depósitos a la vista en las cajas de ahorro (16\%) frente a la banca privada $(13 \%)$ y las cooperativas de crédito (9\%). En la Comunidad Autónoma de Castilla y León se aprecia un comportamiento análogo, mientras que en el ámbito nacional el predominio de los depósitos a plazo mantiene el mismo porcentaje en las tres categorías de agentes (59\%).

\subsection{Créditos}

El volumen total de créditos concedidos por las distintas entidades financieras, tanto al sector público como al sector privado, constituye otra de las variables relevantes de nuestro análisis. La Tabla 4 recoge el importe absoluto y el Gráfico 7 la evolución temporal de los créditos concedidos por las entidades de depósitos de nuestra provincia desde la entrada en la Comunidad Económica Europea hasta la actualidad. 
Tabla 4

Créditos concedidos por las entidades de depósito leonesas durante el periodo 1986-2011 (miles de euros)

\begin{tabular}{|l|c|c|c|c|c|c|c|c|}
\hline & \multicolumn{1}{|c|}{1986} & \multicolumn{1}{c|}{$\mathbf{1 9 9 0}$} & \multicolumn{1}{c|}{$\mathbf{1 9 9 4}$} & \multicolumn{1}{c|}{$\mathbf{1 9 9 6}$} & $\mathbf{2 0 0 0}$ & $\mathbf{2 0 0 4}$ & $\mathbf{2 0 0 8}$ & $\mathbf{2 0 1 1}$ \\
\hline BANCA PRIVADA & $375.861,00$ & $729.382,00$ & $1.131 .832,00$ & $1.243 .344,00$ & $2.068 .636,00$ & $2.964 .000,00$ & $4.536 .177,00$ & $4.398 .624,00$ \\
\hline CAJAS DE AHORRO & $342.282,00$ & $743.386,00$ & $1.305 .987,00$ & $1.654 .935,00$ & $3.043 .061,00$ & $4.154 .000,00$ & $7.613 .029,75$ & $7.329 .307,00$ \\
\hline $\begin{array}{l}\text { COOPERATIVAS DE } \\
\text { CRÉDITO }\end{array}$ & $12.254,64$ & $9.322,00$ & 0 & 0 & $49.129,00$ & $270.000,00$ & $690.438,25$ & $688.909,00$ \\
\hline TOTAL CRÉDITOS & $730.397,64$ & $1.482 .090,00$ & $2.437 .819,00$ & $2.898 .279,00$ & $5.160 .826,00$ & $7.388 .000,00$ & $12.839 .645,00$ & $12.416 .840,00$ \\
\hline
\end{tabular}

Fuente: Dirección General de Estadística. Junta de Castilla y León.

\section{Gráfico 7}

Evolución de los créditos concedidos por las entidades de depósito en León. Periodo 1986-2011

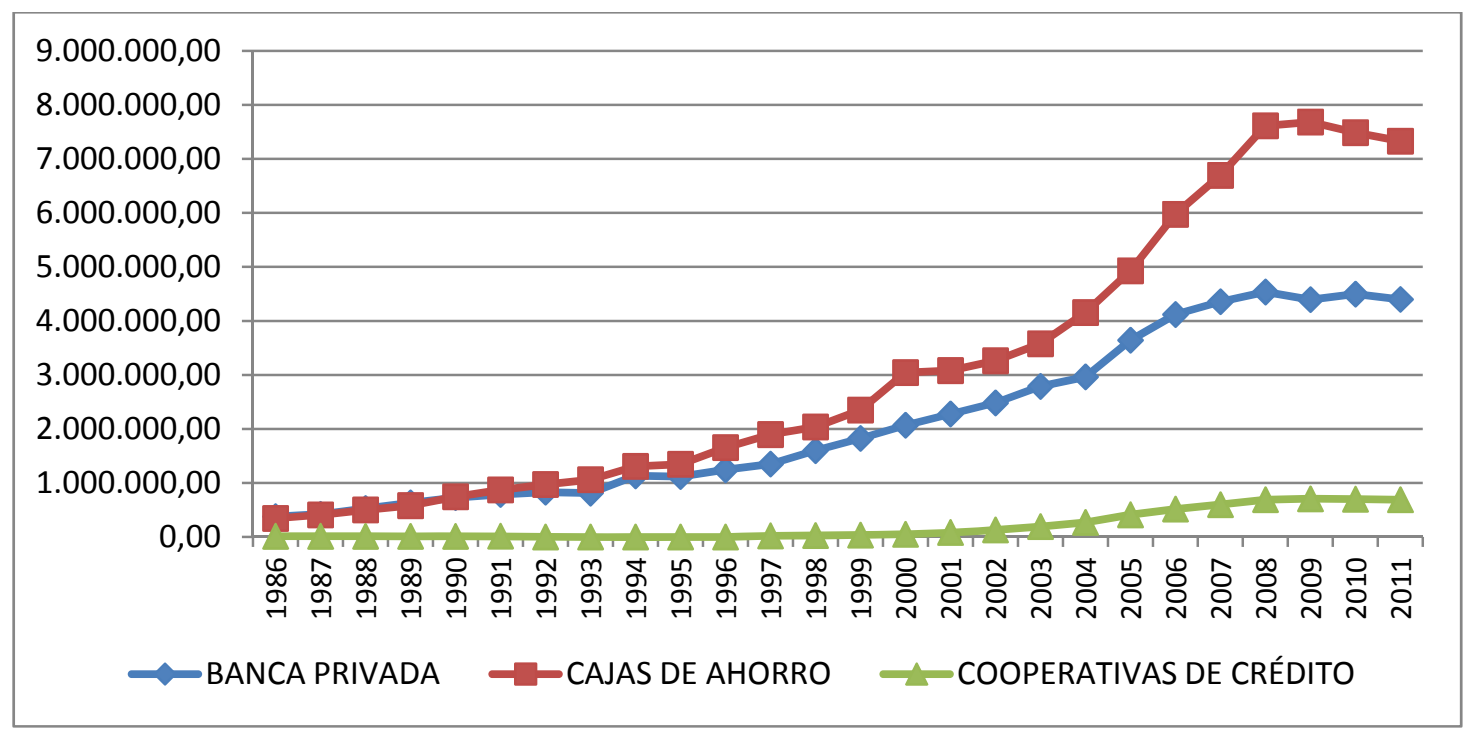

Fuente: Elaboración propia a partir de los datos de la Dirección General de Estadística de la Junta de Castilla y León.

De la observación del Gráfico 7 se deduce una mayor tasa de crecimiento anual de los créditos concedidos por las cajas de ahorros con respecto a la banca privada -en consonancia con el comportamiento anteriormente detectado para los depósitos-, que ha llevado a que a partir de 1990 el volumen total de créditos concedidos por las cajas en León supere al de los bancos ${ }^{5}$, y que la distancia entre ambos tipos de entidades sea cada vez mayor (en 2011 los créditos concedidos por la banca privada en León solamente suponían el $60 \%$ de los concedidos por las cajas de ahorros; en Castilla y León ascendía al $66 \%$ y en España se había invertido la situación de años anteriores

5 Para los depósitos el punto de inflexión se produjo en el año 1993. 
superando los créditos concedidos por la banca privada a los concedidos por las cajas de ahorros en un 3\%.). En Castilla y León desde el año 1986 el volumen de créditos concedidos por las cajas supere al de la banca privada, mientras que en España tal circunstancia se retrasa hasta el año 2005. Estos datos ponen de manifiesto el creciente protagonismo inversor de las cajas de ahorros en León con respecto al que manifiestan a nivel nacional, y confirman la ganancia en cuota de mercado de las cajas a costa de la banca privada en todos los ámbitos analizados. No obstante, otro hecho destacable que se desprende de la observación del Gráfico 7, es el paulatino descenso del importe de créditos totales concedidos por las cajas de ahorros a partir del año 2009 como consecuencia de la restricción del crédito ocasionada por las dificultades financieras por las que están pasando las cajas. En el ámbito de la banca privada también se produce una cierta ralentización, pero no un descenso tan acusado.

El volumen de créditos concedidos por las cooperativas de créditos es el que mayor porcentaje de crecimiento ha tenido a lo largo del periodo, aunque su importancia relativa se mantiene en León en niveles inferiores al $5 \%$.

\section{Gráfico 8}

\section{Créditos concedidos en León por sectores. Periodo 1986-2012}

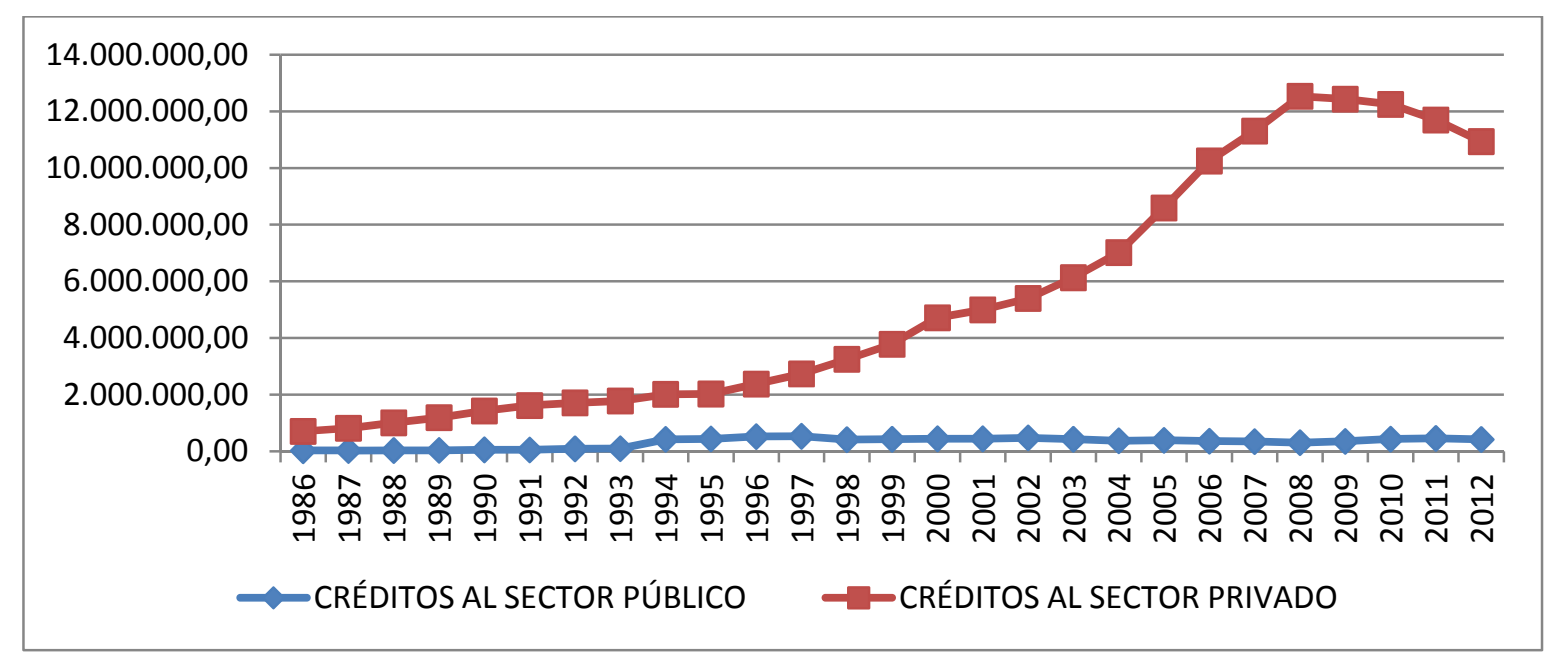

Fuente: Elaboración propia a partir de los datos de la Dirección General de Estadística de la Junta de Castilla y León.

Entrando en el estudio de los agentes a los que se conceden los créditos, se observa un mayor crecimiento de los créditos concedidos al sector privado a lo largo del periodo considerado (Gráfico 8), manteniéndose en torno al $3 \%$ del total el volumen de créditos concedidos a las Administraciones Públicas, con una importancia relativa escasa ${ }^{6}$. Un comportamiento similar se produce en Castilla y León y España.

\footnotetext{
6 Excepto en el sector de las cooperativas de crédito, donde los créditos al sector público apenas se producen, no llegando a suponer en ninguno de los ámbitos considerados ni siquiera un $0,2 \%$ del total.
}

El Gráfico 9 muestra las tasas de penetración en los créditos concedidos en la provincia de León de banca privada, cajas de ahorros y cooperativas de crédito en los dos años extremos del intervalo temporal considerado. La tasa de penetración de los créditos concedidos por la banca privada en León ha descendido paulatinamente a los largo del periodo considerado; así, del $51 \%$ que suponía del total de créditos concedidos en 1986 se ha pasado al $35 \%$ en 2011. En cambio, como cabía esperar en virtud de lo anteriormente expuesto, la tasa de penetración de las cajas de ahorro y de las cooperativas de crédito han experimentado un 
comportamiento contrario. Las cajas de ahorros, por ejemplo, han pasado del $47 \%$ al $59 \%$, mientras que las cooperativas lo hacian del $2 \%$ al $6 \%$. En Castilla y León, la tasa de penetración crediticia de la banca privada también ha descendido, si bien se mantiene en el $36 \%$ en el año 2011. Por su parte, la cuota correspondiente a cajas de ahorros se sitúa en el $54 \%$ para 2011 y la de las cooperativas de crédito en el $10 \%$.

\section{Gráfico 9}

Tasa de penetración por agentes en los créditos concedidos. Años 1986 y 2011
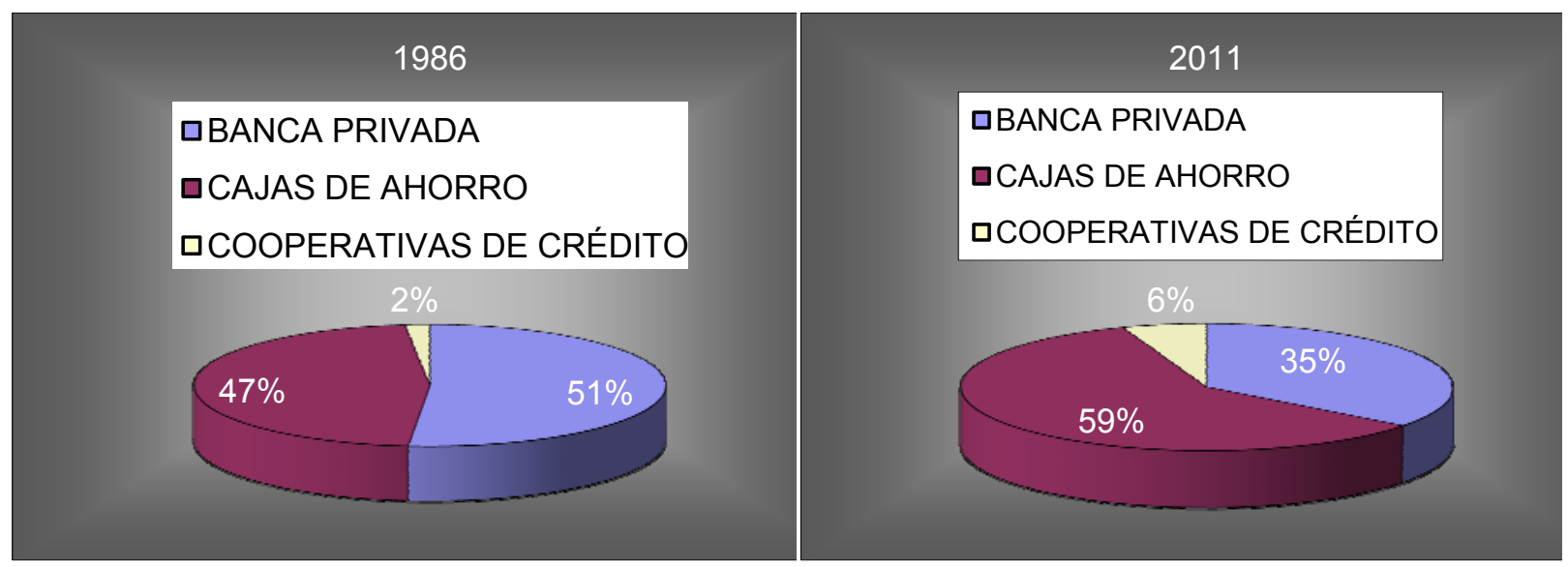

Fuente: Elaboración propia a partir de los datos de la Dirección General de Estadística de la Junta de Castilla y León.

En el territorio nacional, la tasa de penetración de los créditos concedidos por la banca privada también ha descendido de manera importante en 21 puntos porcentuales -del $68 \%$ en 1986 al $48 \%$ en 2011-, aunque continúa situándose muy por encima de la que le corresponde en León y Castilla y León. Las cajas de ahorros, por su parte, pasan de una tasa del $29 \%$ en 1986 al $47 \%$ en 2010 alcanzando valores similares a los de la banca, con una escasa diferencia de un punto porcentual.

De lo expuesto se deduce un mayor protagonismo en el proceso inversor de las cajas de ahorros en León y Castilla y León, que el que manifiestan en España, donde la banca privada sigue conservando tasas importantes, aunque también decrecientes.
La comparación entre los datos relativos a la inversión crediticia y los relativos al volumen de depósitos nos muestra para el año 2012 un mayor peso de la primera de las variables en los tres ámbitos considerados (Gráfico 10), aunque a esa situación se ha llegado en diferentes momentos del periodo analizado -en la Provincia y en la Comunidad Autónoma en el año 2005 y en España seis años antes-. Por categorías de entidades de depósito se observan, sin embargo, diferencias relevantes, pues mientras en bancos y cooperativas de crédito, los créditos concedidos superan en valor a los depósitos captados en la provincia desde el año 2002 y 1997 respectivamente, en cambio en el sector de cajas de ahorros la inversión crediticia no llega a superar al importe de los depósitos hasta el año 2006. 


\section{Gráfico 10}

Comparación del volumen de créditos y depósitos en León. Periodo 1986-2012

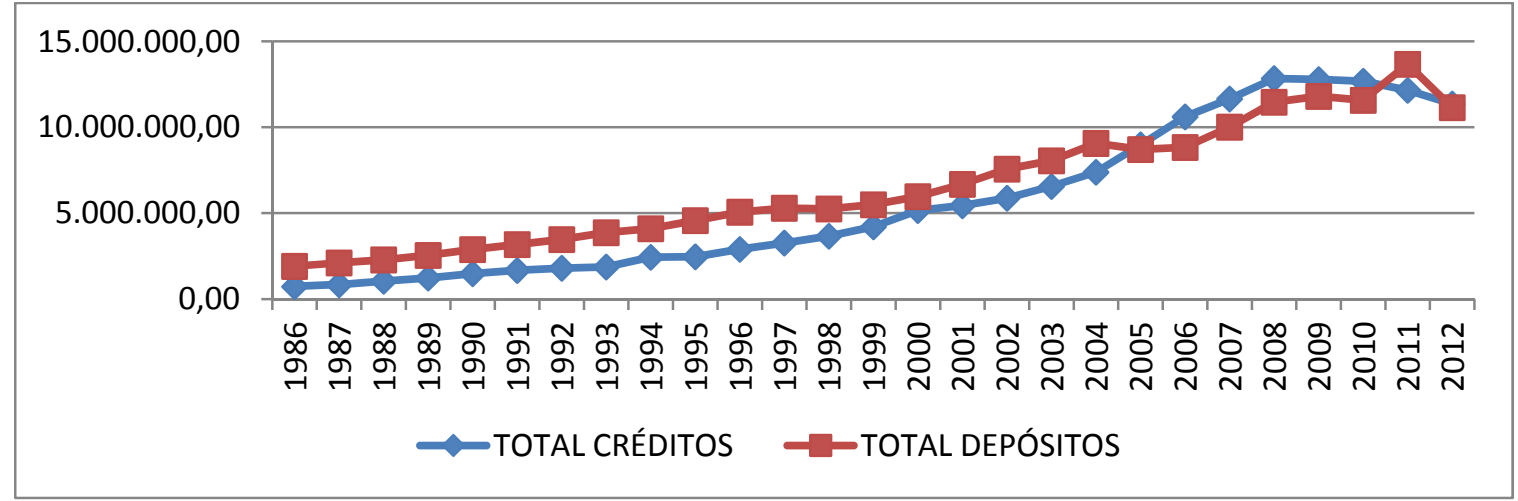

Fuente: Elaboración propia a partir de los datos de la Dirección General de Estadística de la Junta de Castilla y León.

El hecho de que el volumen de créditos supere al de depósitos en los últimos años se puede explicar atendiendo a las tasas de crecimiento imperantes en ese periodo en la economía española que se han situado anualmente en porcentajes superiores al $3 \%$, y en particular al desmesurado crecimiento del crédito a la construcción, posibilitando una burbuja inmobiliaria que terminó por estallar en el año 2007. El mantenimiento de esos niveles de crecimiento del PIB implica dinamismo en el proceso inversor de las empresas en los diferentes sectores de la industria, lo que ha exigido volúmenes de financiación, importantes y crecientes, concedidos en gran parte por bancos y cajas de ahorros, y no siempre viniendo precedidos de un riguroso análisis de riesgos ${ }^{7}$.

\footnotetext{
7 En el año 2013, cuando se están redactando estas líneas, en plena crisis financiera nacional e internacional, los ciudadanos siguen pagando las consecuencias de las dificultades financieras por las que han pasado muchas entidades de crédito, como consecuencia de no haber evaluado rigurosamente sus riesgos y haber tenido excesiva manga ancha en la concesión de financiación a determinados sectores como el de las empresas constructoras e inmobiliarias.
}

\subsection{Hipotecas}

Otra variable relevante en el análisis del sector financiero leonés lo constituyen las hipotecas constituidas. La estadística de hipotecas proporciona mensualmente información sobre el número de bienes hipotecados y la cuantía de los préstamos hipotecarios concedidos por bancos, cajas de ahorros y otras entidades. Dicha información se obtiene de los Registros de la Propiedad $^{8}$ y es elaborada por el Instituto Nacional de Estadística.

\footnotetext{
8 Desde 1954, año en que comenzó a elaborarse la estadística de hipotecas, la fuente de información estaba constituida por cada uno de los Registros de la Propiedad a través de un cuestionario normalizado en soporte papel, A partir de enero de 2004, en virtud de un convenio firmado por el Colegio de Registradores de la Propiedad y Mercantiles de España y el Instituto Nacional de Estadística, es el citado Colegio a través del Servicio de Sistemas de Información, quien suministra de forma centralizada al INE la información mediante soporte magnético. Por ello, en las estadísticas de hipotecas publicadas por el INE se distinguen dos series de datos, hasta 2003 elaborados con la metodología antigua, y a partir de 2004 con la nueva metodología. Los datos del año 2003 se presentan conforme a ambas metodologías. A pesar de que a partir de 2004 la información es más amplia y correcta, las series temporales no muestran comportamientos dispares, por lo que a nuestro juicio pueden ser analizadas conjuntamente.
} 
El Gráfico 11 nos muestra la evolución del número de fincas urbanas y rústicas hipotecadas en León desde el año 1991.

Mientras el número de fincas rústicas hipotecadas mantiene oscilaciones año tras año en torno a las 300 , doblando ese número en el año 2012, en cambio el número de fincas urbanas (viviendas, solares, etc.) sufre un fuerte incremento, siendo necesario multiplicar prácticamente por cuatro la cifra del año 1991 (3.649 fincas) para obtener la del año 2007 (17.064 fincas). Este incremento es especialmente significativo desde el año 2003, coincidiendo con el periodo en que la economía española creció a tasas superiores al 3\%, lo que revela que en épocas de crecimiento económico los ciudadanos se animan a invertir en el mercado inmobiliario y las entidades de depósito flexibilizan las condiciones de acceso a las hipotecas ${ }^{9}$. Sin embargo a partir del año 2008 el número de fincas hipotecadas desciende fuertemente coincidiendo con la crisis financiera y con la consiguiente restricción del crédito vinculado al sector de la construcción, situándose en el año 2012 en una cuarta parte del número de fincas urbanas hipotecadas en el año 2008.

\section{Gráfico 11}

Número de fincas urbanas y rústicas hipotecadas en León. Periodo 1991-2012
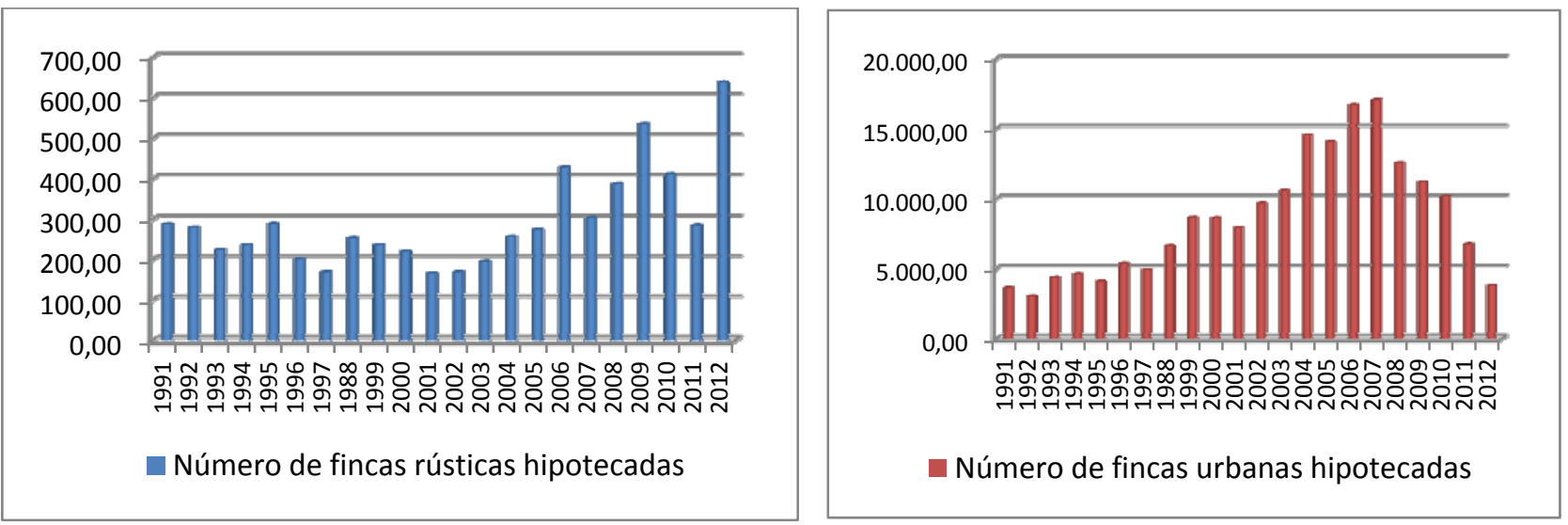

Fuente: Elaboración propia a partir de los datos de la Dirección General de Estadística de la Junta de Castilla y León.

Si desglosamos las fincas rústicas en viviendas, solares y otras, se observa cómo son las viviendas el colectivo de fincas hipotecadas que más creció en el periodo analizado, seguido por el de otras fincas urbanas, y a bastante distancia por el de solares (véase el Gráfico 12). A partir del año 2007, también es el grupo de viviendas el que ha sufrido las mayores caídas.

\footnotetext{
9 El incremento de las hipotecas que se produce en el año 2003 puede venir en parte explicado por el cambio en la metodología del cómputo estadístico de las hipotecas, si bien la serie temporal no muestra comportamientos llamativos en dicho año.
} 


\section{Gráfico 12}

\section{Desglose de las fincas urbanas hipotecadas en León. Periodo 1991-2012}

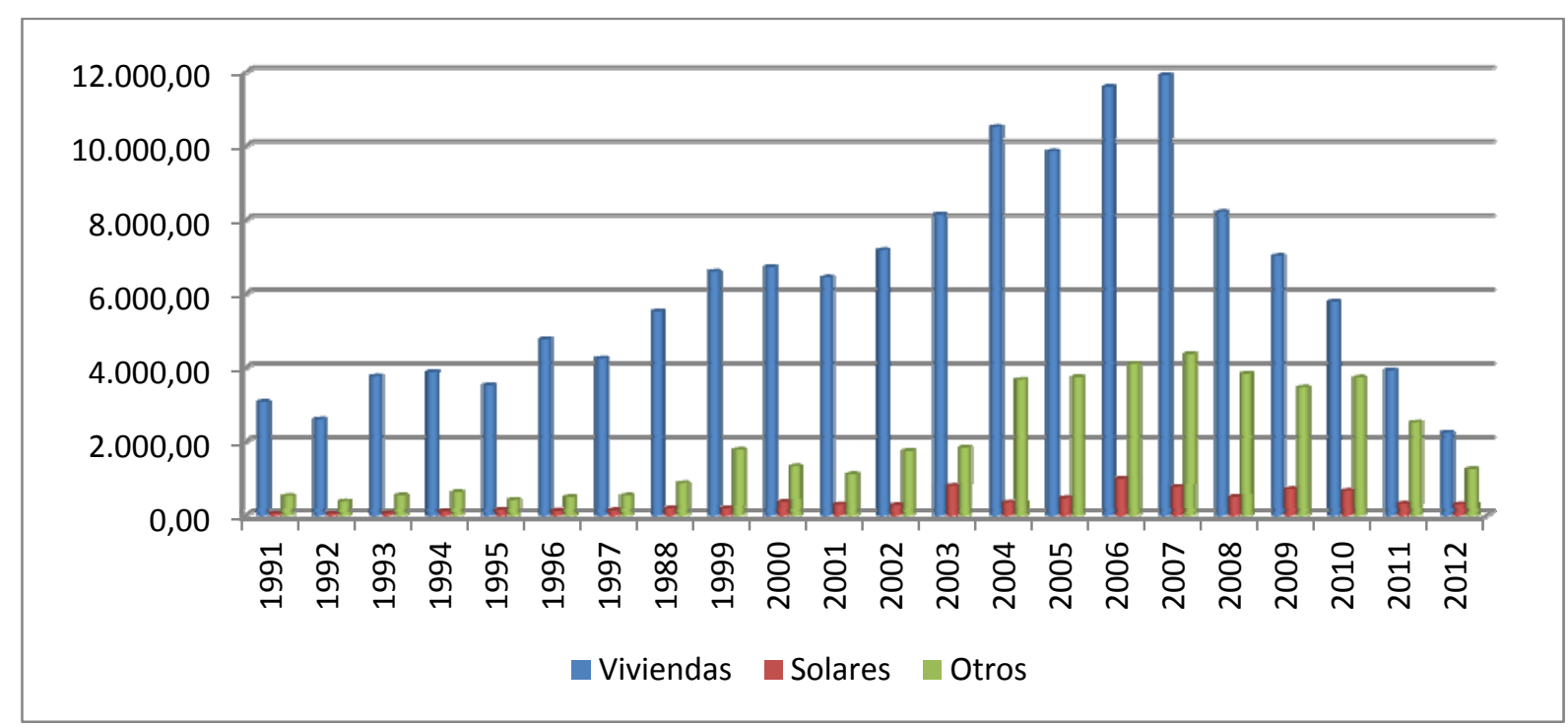

Fuente: Elaboración propia a partir de los datos de la Dirección General de Estadística de la Junta de Castilla y León.

En cuanto a la composición interna de las fincas urbanas hipotecadas, sin embargo, el colectivo de viviendas hipotecadas, ha perdido peso respecto a los otros dos colectivos, aunque su cuota de participación continúa siendo la más importante (74\% en 1991 y 56\% en 2012). Los solares pasan del $8 \%$ al $6 \%$ en el mismo periodo y la categoría de otras fincas urbanas hipotecadas del $18 \%$ al $38 \%$. En el ámbito de la Comunidad Autónoma de Castilla y León, el peso relativo de las viviendas hipotecadas también ha ido decreciendo dentro del total y se mantiene en porcentajes similares a los de la provincia leonesa (57\% en 2012); por su parte, el peso de los solares ha crecido a lo largo del periodo y se sitúa en el $15 \%$ en el año 2012. A nivel nacional, se observan trayectorias similares a las de la provincia en cuanto a la composición interna de las fincas urbanas hipotecadas, con pesos relativos similares de cada categoría de activos.

Además del estudio del número de fincas hipotecadas, resulta interesante observar la evolución del capital hipotecado (Gráficos 13 y 14), no apreciándose comportamientos diferentes a los anteriormente comentados excepto por lo que hace referencia al capital de fincas rústicas hipotecadas que aumenta de manera considerable a lo largo del periodo. Mientras en el número de fincas rústicas hipotecadas no había variaciones importantes, en cambio, el capital crece fuertemente desde el año 2003, llegando en el año 2007 a multiplicar por 10 la cifra del año 1991. A nivel de Castilla y León, el crecimiento del capital hipotecado en fincas rústicas es bastante superior al que se aprecia en el ámbito provincial. 


\section{Gráfico 13}

Capital de las fincas urbanas hipotecadas en León. Periodo 1991-2012

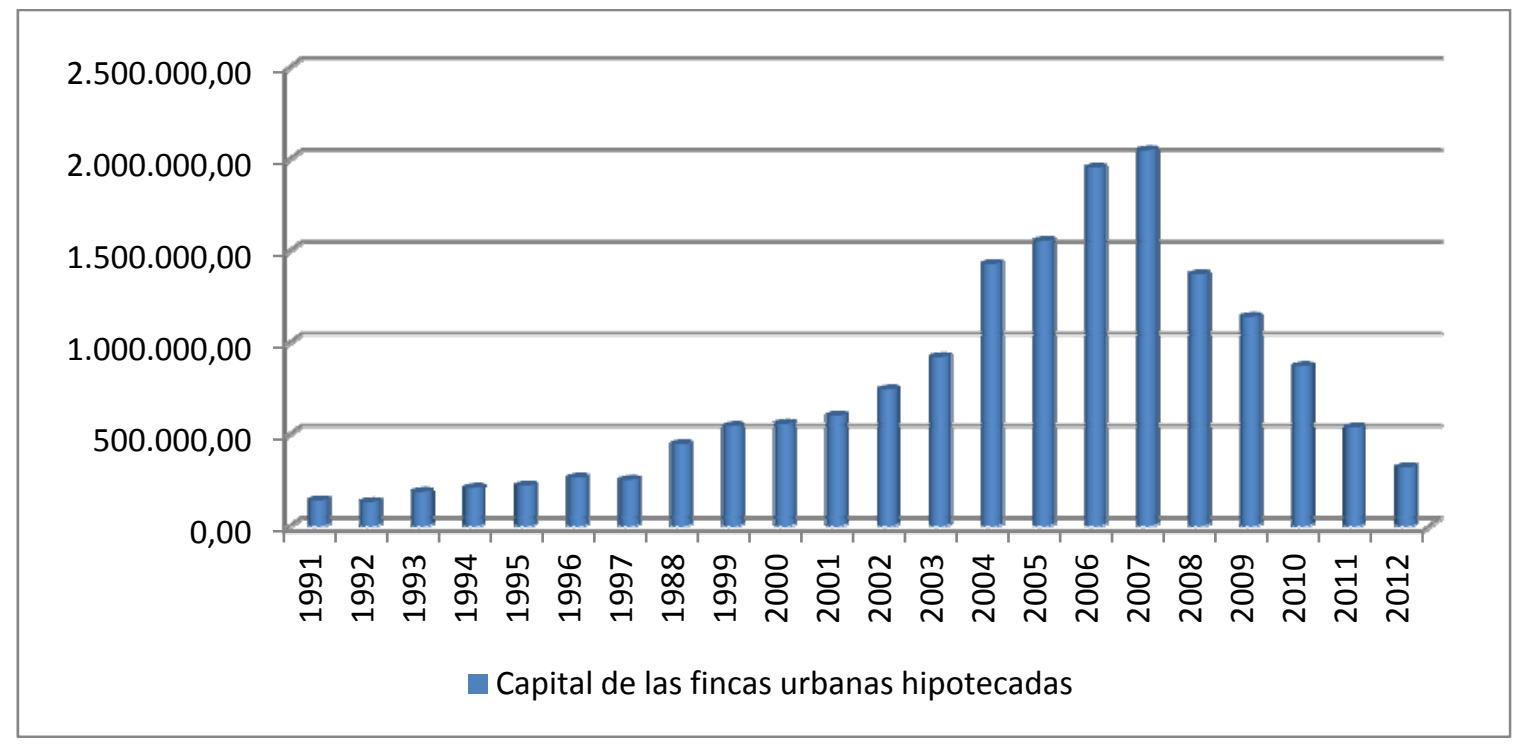

Fuente: Elaboración propia a partir de los datos de la Dirección General de Estadística de la Junta de Castilla y León.

\section{Gráfico 14}

Capital de las fincas rústicas hipotecadas en León. Periodo 1991-2012

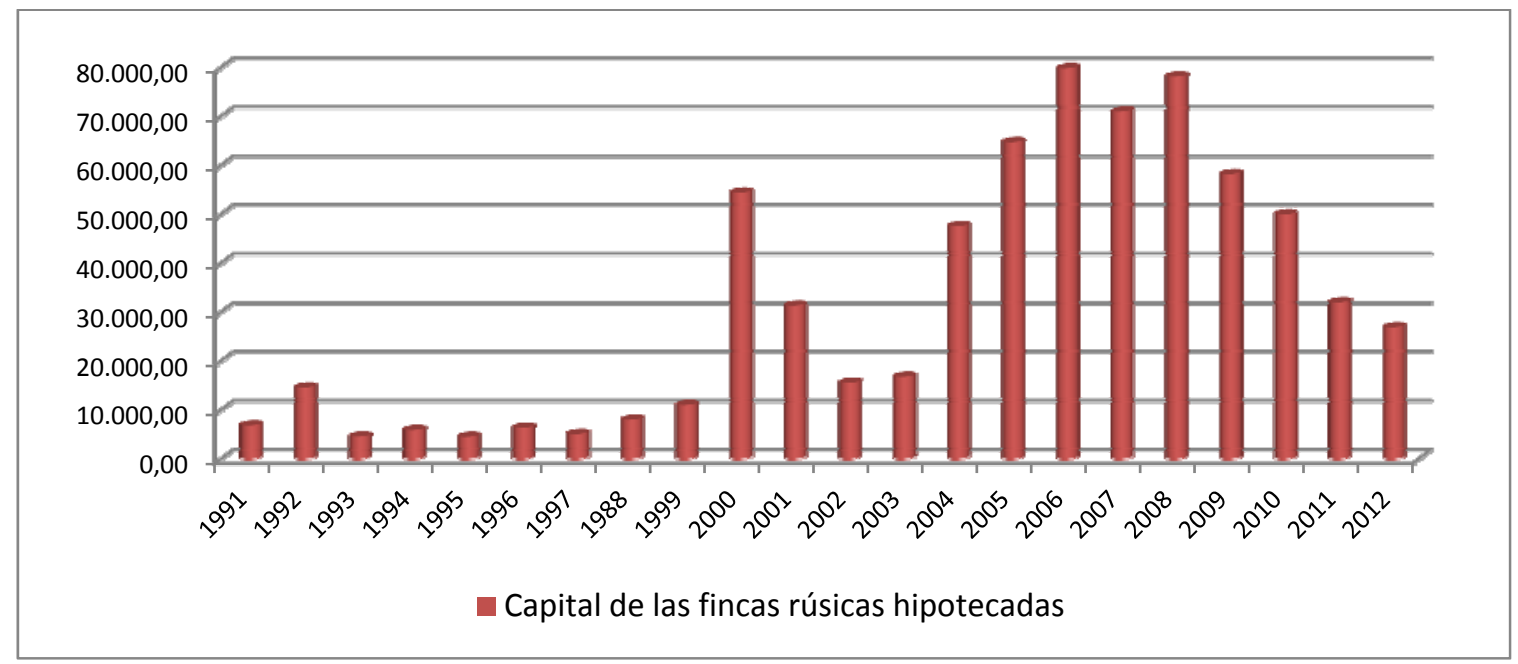

Fuente: Elaboración propia a partir de los datos de la Dirección General de Estadística de la Junta de Castilla y León.

Respecto a la evolución y composición interna del capital de las fincas urbanas hipotecadas (Gráfico 15), el único hecho diferencial que conviene poner de relieve hace referencia a la participación relativa de las viviendas dentro de las fincas urbanas hipotecadas que en capital mantienen un peso inferior al anteriormente comentado respecto al número (suponen el $74 \%$ del total en el año 
1991, y descienden al 56\% en el año 2012). Los solares, por su parte, suponen un mayor porcentaje del total en capital que en número $(8 \%$ en 1991 y $6 \%$ en 2012). En Castilla y León, el peso del capital hipotecado en viviendas también ha ido decreciendo, situándose en el año 2010 en el $57 \%$ del total. Por su parte, la cuota correspon- diente a las categorías de solares y otras fincas urbanas son superiores a las de León $(16 \%$ en el año 2007 para los solares y $30 \%$ para la categoría residual). En España, se observa una evolución y composición del capital hipotecado similar al comentado para la provincia.

\section{Gráfico 15}

\section{Capital de las fincas urbanas hipotecadas en León. Periodo 1991-2012}

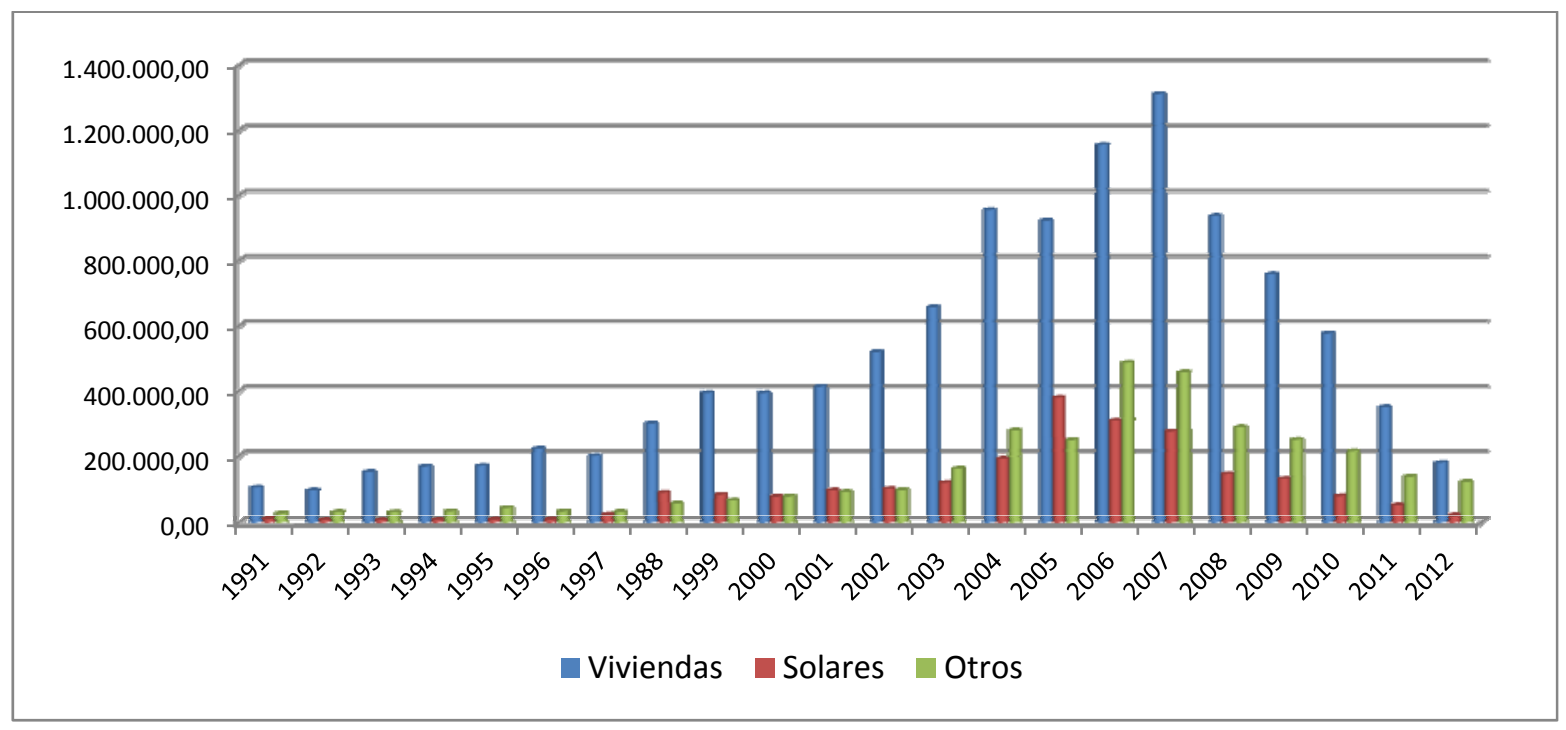

Fuente: Elaboración propia a partir de los datos de la Dirección General de Estadística de la Junta de Castilla y León.

De la observación de los gráficos relativos a la evolución de las hipotecas durante el periodo 1991-2012 se deduce con claridad el tremendo descenso que se ha producido desde el desencadenamiento de la crisis financiera internacional y que ha conducido a que las hipotecas del año 2012 se sitúen en niveles similares a las de los años 1992 o 1993 y representen apenas un $15 \%$ de las concedidas en el año 2007.

\subsection{Indicadores}

El análisis mediante indicadores constituye la última de las fases del estudio del sector financiero en la provincia de León. Estos indicadores pueden resumirse en tres grandes grupos. En primer lugar, se calculan tres ratios cuyo objetivo común es realizar una aproximación el grado de bancarización imperante en los distintos ámbitos geográficos y entidades financieras consideradas; dichos ratios son el número de oficinas por cada 10.000 habitantes, el volumen de créditos por habitante y el importe de depósitos por habitante. Un segundo grupo de ratios, integrado por los índices de depósitos y de créditos por oficina y el número de empleados por oficina, es el encargado de medir el tamaño medio de las entidades financieras. Finalmente, la productividad del personal empleado se expresa a través del importe de depósitos y de créditos por trabajador. Los cuadros recogen todos estos ratios, siempre que las variables correspondientes estén disponibles, para el conjunto de entidades financieras, banca privada, cajas de ahorro y cooperativas de crédito. 


\subsubsection{Grado de bancarización}

Cuando se mide el grado de bancarización mediante el número de oficinas por cada 10.000 habitantes se observa como la trayectoria seguida por este indicador durante los últimos diez años en León se ha mantenido prácticamente constante y se aproxima mucho a la de España, situándose en torno a 10 oficinas por cada 10.000 habitantes. Únicamente cabe destacar, como hecho diferencial, el ligero repunte que se produce en la provincia desde el año 2002, que permite alcanzar en el año 2008 un indicador de 10,98 oficinas por cada 10.000 habitantes, cifra que aún queda lejana del valor de este indicador en la Comunidad Autónoma de Castilla y León donde se sitúa para todo el periodo en cifras cercanas al 12\% (Gráfico 16). Sin embargo a partir del año 2008 en los tres ámbitos territoriales analizados se produce un paulatino descenso, bastante más acusado en castilla y León y España que en la provincia de León ${ }^{10}$.

\section{Gráfico 16}

\section{Número de oficinas por cada 10.000 habitantes. Periodo 1998-2011}

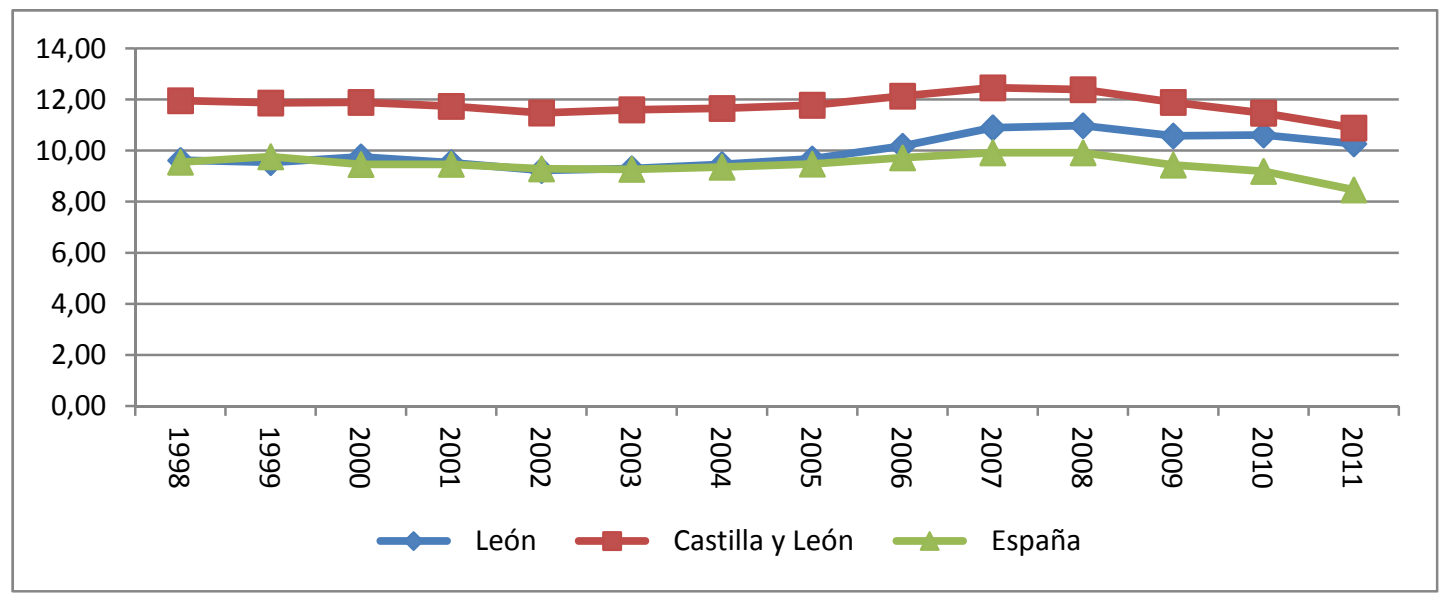

Fuente: Elaboración propia a partir de los datos de la Dirección General de Estadística de la Junta de Castilla y León.

Cuando desglosamos el número de oficinas por cada 10.000 habitantes por categorías de entidades de depósito, vemos como el grado de bancarización de la banca privada ha ido descendiendo paulatinamente en León desde el año $1998(5,49)$ hasta el año $2011(4,22)$ lo que supone un descenso del $23 \%$. En cambio, el correspondiente a las cajas de ahorros y cooperativas de crédito, presenta la trayectoria contraria pasando de 3,99 oficinas en el año 1988 a 5,42 oficinas en el año 2011 (incremento de un 35\%) para las cajas, y de 0,14 a 0,62 oficinas por cada 10.000 habitantes para las cooperativas de crédito. También en este terreno se observa el diferente comportamiento que bancos y cajas han venido teniendo durante la última década. Comparando con Castilla y León y España, resalta el menor grado de ban-

10 Según el Instituto de Estudios Bursátiles España es el país con mayor porcentaje de oficinas bancarias por habitante, y el cuarto país del mundo con más oficinas cuando ni siquiera estamos entre las diez primeras potencias económicas, lo que revela con claridad un exceso de capacidad instalada (Fernández Brando, T. et alt., 2012). 
carización de las cooperativas de crédito en León, el mayor de las cajas en la Comunidad Autónoma y de la banca privada en León con respecto al de la Comunidad Autónoma y al de España.

\section{Gráfico 17}

\section{Créditos y depósitos por habitante en León, Castilla y León y España}

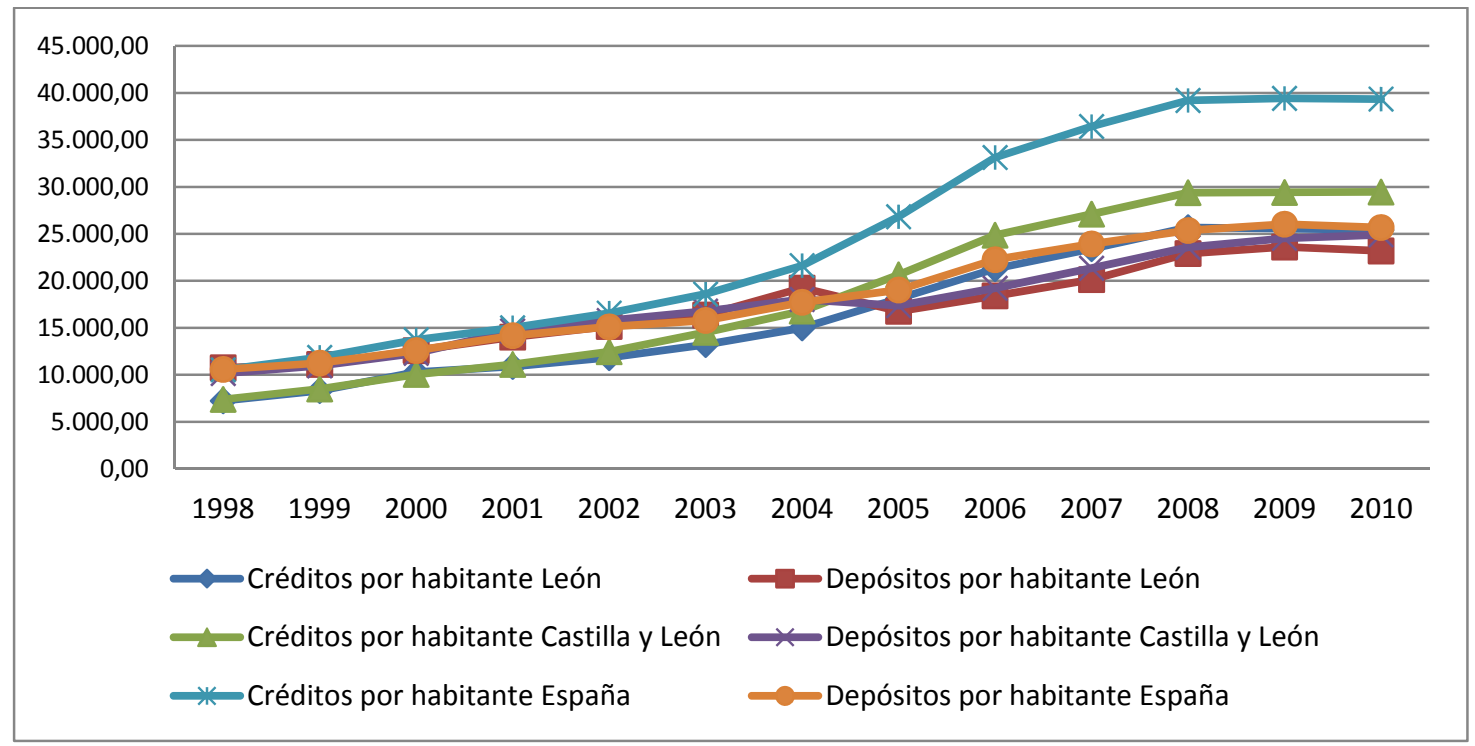

Fuente: Elaboración propia a partir de los datos de la Dirección General de Estadística de la Junta de Castilla y León.

Si nos centramos, ahora, en el estudio de las ratios créditos por habitante y depósitos por habitante (Gráfico 17) se constata cómo de una situación inicial en el año 1998 en la que el importe de los depósitos por habitante superaba al de los créditos en los tres ámbitos considerados, provincial, autonómico y nacional, se pasa paulatinamente a otra en la que el importe de los créditos por habitante supera ampliamente al de depósitos, llegando al año 2011 en que en León los créditos per cápita superan a los depósitos en un $2 \%$ (en Castilla y León en un $13 \%$ y en España en un 53\%). Se observa, además, cómo el indicador créditos por habitante se mantiene en León $(22.968 €)$ muy por debajo de Castilla y León $(27.747 €)$ y España $(37.372 €)$.

Por su parte, analizando estos indicadores por categorías de entidades de depósito se comprueba que el indicador de créditos por habitante en la banca privada en España prácticamente dobla al de León y la Comunidad Autónoma, mientras que en las cajas de ahorro apenas se observan diferencias en los tres ámbitos considerados. También destaca el menor peso de los créditos y depósitos por habitante de las cooperativas de crédito en León con respecto a Castilla y León y España. Se confirma, por tanto, el mayor protagonismo en el grado de bancarización de las cajas en la provincia, con respecto a la banca privada y las cooperativas de crédito.

\subsubsection{Tamaño medio de las oficinas}

El tamaño medio de las oficinas puede estudiarse mediante varios indicadores, tales como el importe de créditos y depósitos por oficina y el número medio de empleados por oficina.

El Gráfico 18 nos muestra la evolución de los créditos y depósitos por oficina en el ámbito provincial, autonómico y nacional; resalta el menor importe de depósitos y especialmente de créditos por oficina tanto en León como en Castilla y León con respecto a España, lo que se explica por el elevado número de oficinas 
bancarias existentes en nuestra región, de manera que se sigue un modelo organizativo de oficina pequeña, adecuado al tipo de servicios que requieren las características y la densidad geográfica de la demanda. Además, en el ámbito nacional el importe de créditos por empleado se mantiene por encima del de depósitos desde 1999, mientras que en León y Castilla y León tal circunstancia se produce a partir de 2005 poniendo de manifiesto el singular retraso de nuestra región en la adaptación a las tendencias seguidas por las finanzas de la nación.

\section{Gráfico 18}

\section{Créditos y depósitos por oficina en León, Castilla y León y España}

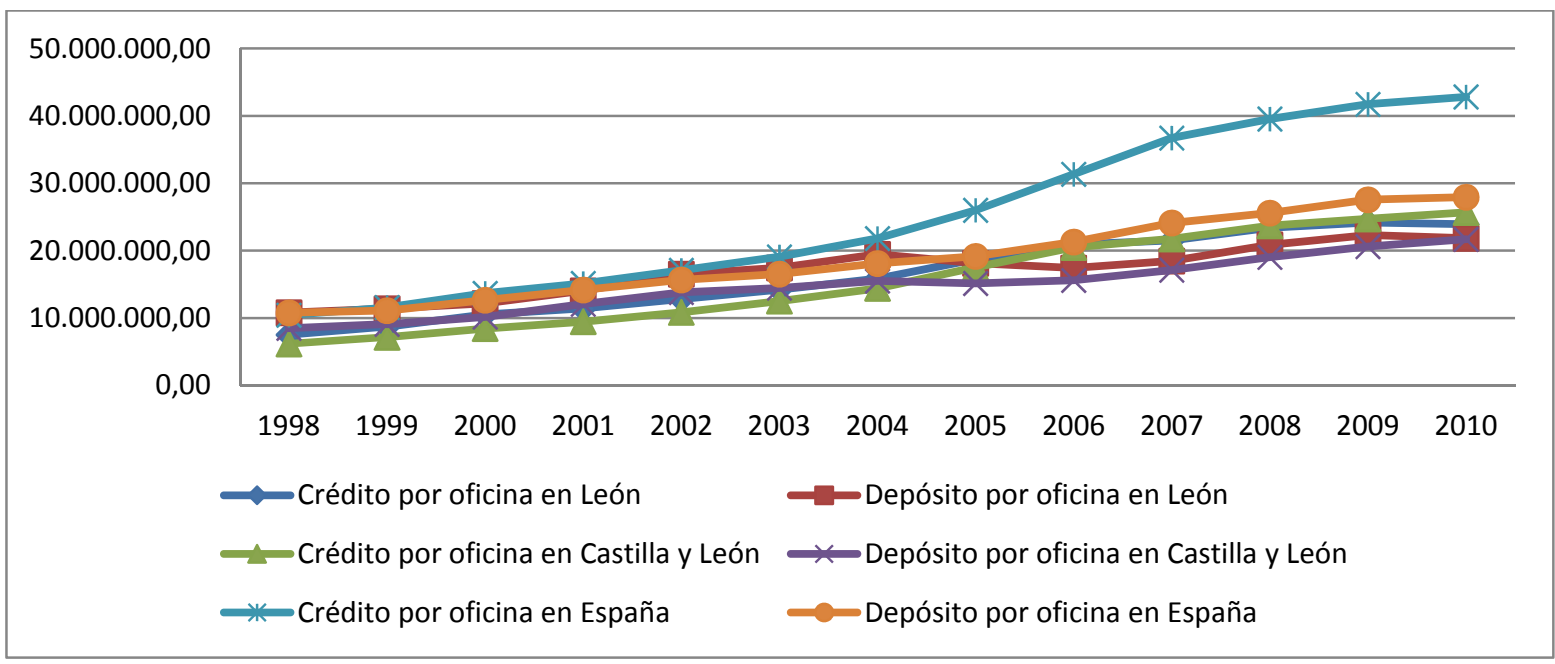

Fuente: Elaboración propia a partir de los datos de la Dirección General de Estadística de la Junta de Castilla y León.

Por agentes, el tamaño medio de las oficinas de la banca privada en España, en cuanto al volumen de créditos y depósitos por oficina, es muy superior al de Castilla y León y al de la provincia; así, mientras en España en el año 2012 asciende a 62 millones de $€$ para los créditos y a 40 millones para los depósitos, en Castilla y León se reduce a 30 y 25 millones de $€$ respectivamente, y en León a 20 y 22 millones de $€$. Respecto a las cajas de ahorros se encuentran menores diferencias, situándose con valores superiores a los de los bancos en León, ligeramente inferiores a aquellos en Castilla y León, y muy inferiores en el ámbito nacional.

La ratio número medio de empleados por oficina solamente se ha podido calcular a nivel provincial para el sector de banca privada observándose un paulatino descenso en los tres ámbitos territoriales considerados a lo largo del periodo 19982011 (véase el Gráfico 19). Destaca en este tema que el número de empleados por oficina en la banca privada en León es inferior al de la Comunidad Autónoma, y éste inferior a su vez al de España; así, por ejemplo, refiriéndonos al año 2011, el valor de la ratio citada se sitúa en León en 4,34 empleados de media por oficina, en Castilla y León en 4,89 y en España en 7,5. De hecho, en León se ha producido a lo largo del periodo anteriormente citado un mayor descenso en el número de empleados (un 32\%) que en el número de oficinas (un 22\%), poniendo de manifiesto el ajuste laboral que las entidades financieras han llevado a cabo en los últimos años ${ }^{11}$.

11 Con respecto al número medio de empleados por oficina de caja de ahorros y cooperativas de créditos, solamente se dispone del dato global para todo el país, manteniéndose prácticamente constante para las primeras en valores en torno a 5,4 empleados por oficina, y con una tendencia claramente creciente para las segundas (pasan de una media de 3,6 empleados por oficina en 1999 a 4,1 en el año 2011. 


\section{Gráfico 19}

Número de empleados por oficina. Banca privada. 1995-2011

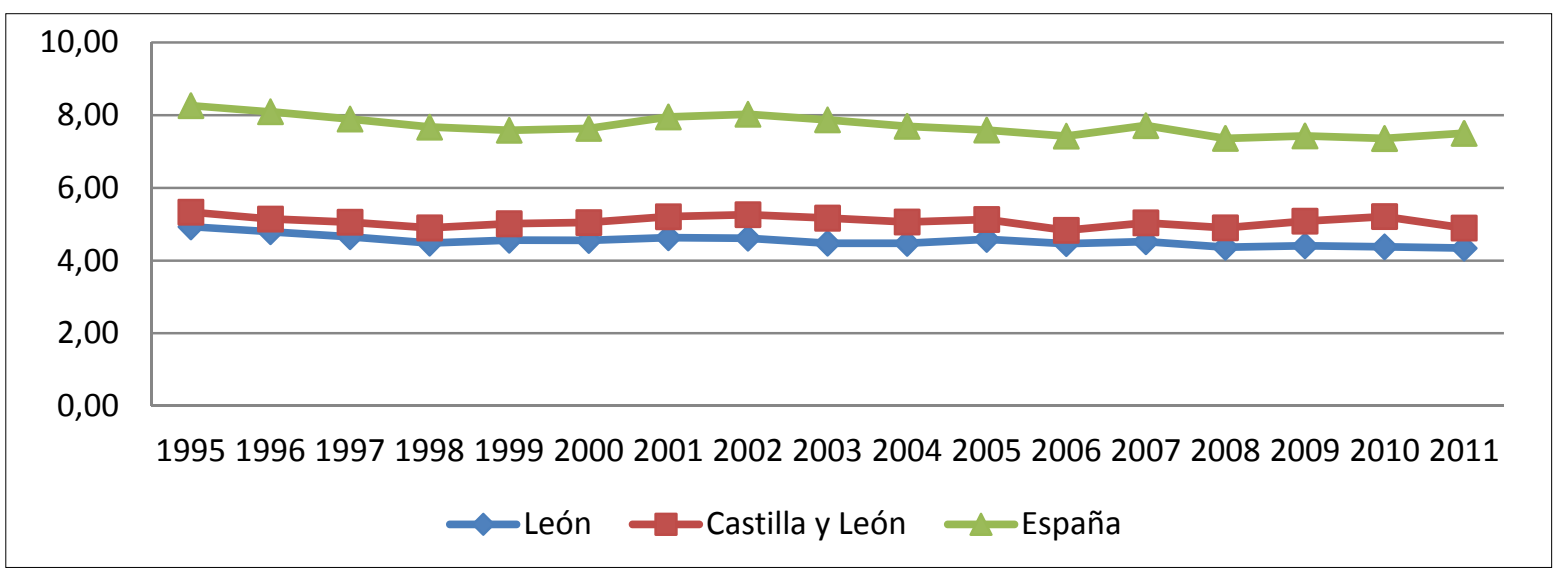

Fuente: Elaboración propia a partir de los datos de la Dirección General de Estadística de la Junta de Castilla y León.

\subsubsection{Produc tividad del personal}

La productividad del personal se puede analizar mediante indicadores que relacionan el importe de créditos y depósitos por empleado, si bien hemos de constatar las dificultades que hemos encontrado a la hora de disponer de datos relativos al número de empleados de cajas de ahorros y de cooperativas de crédito en la provincia y comunidad autónoma. Para estas dos categorías de entidades solamente hemos podido calcular el valor de estos dos indicadores a nivel nacional.

Del análisis del valor de los indicadores calculados se deduce como en León, en el ámbito de la banca privada, el importe de depósitos por empleado ha excedido al de créditos por empleado durante el periodo 2001-2010. Se observa, además, una tendencia claramente creciente desde el año 1998, tanto en los créditos como en los depósitos por empleado, si bien la pendiente de la curva relativa a los depósitos sufre una cierta ralentización a partir del año 2003. Los años de fuerte crecimiento de la economía española aceleraron la actividad crediticia, sin que la captación de depósitos pudiera mantener un ritmo similar. Sin embargo, en el año 2011 se vuelve a la situación existente con anterioridad al año 2001 y los depósitos por empleado vuelven a superar a los créditos. Se observa con claridad en el Gráfico
20 los efectos multiplicadores de la burbuja inmobiliaria sobre los créditos concedidos

Para Castilla y León y España la situación de estos indicadores para la banca privada es similar hasta el año 2010, aunque la distancia entre el volumen de créditos por empleado sobre el de los depósitos es mayor para el año 2010 (27\% en Castilla y León y $60 \%$ en España). Además, a nivel nacional, durante los últimos diez años los créditos por empleado superan a los depósitos por empleado ampliándose a cada año el diferencial entre unos y otros. En el año 2011, mientras en León el importe de los depósitos por empleado supera al de los créditos, en cambio, tanto en el ámbito territorial autonómico como en el nacional, los créditos por empleado siguen estando muy por encima de los depósitos por empleado.

En cuanto a los créditos y depósitos por empleado en las cajas de ahorros, solamente disponemos de los datos a nivel nacional, detectándose una diferencia sustancial con respecto al sector de la banca privada, pues hasta el año 2003 el importe de créditos por empleado no superó al de depósitos y llegando al año 2011 en que el indicador obtiene un valor inferior para los créditos $(7.436 .479,60 €$ y para los depósitos (4.946.002 $€$ ). En las cooperativas de crédito, a nivel nacional, los créditos por empleado superan a los depósitos a partir del año 2006, aunque la productividad de los 
empleados es inferior a la de los otros dos colectivos de entidades de depósito (4.888.526 $€$ para los créditos por empleado y $4.017 .703 €$ para los depósitos per cápita, ambos datos correspondientes al año 2011).

\section{Gráfico 20}

\section{Créditos y depósito por empleado de la banca privada en León. Periodo 1998-2011}

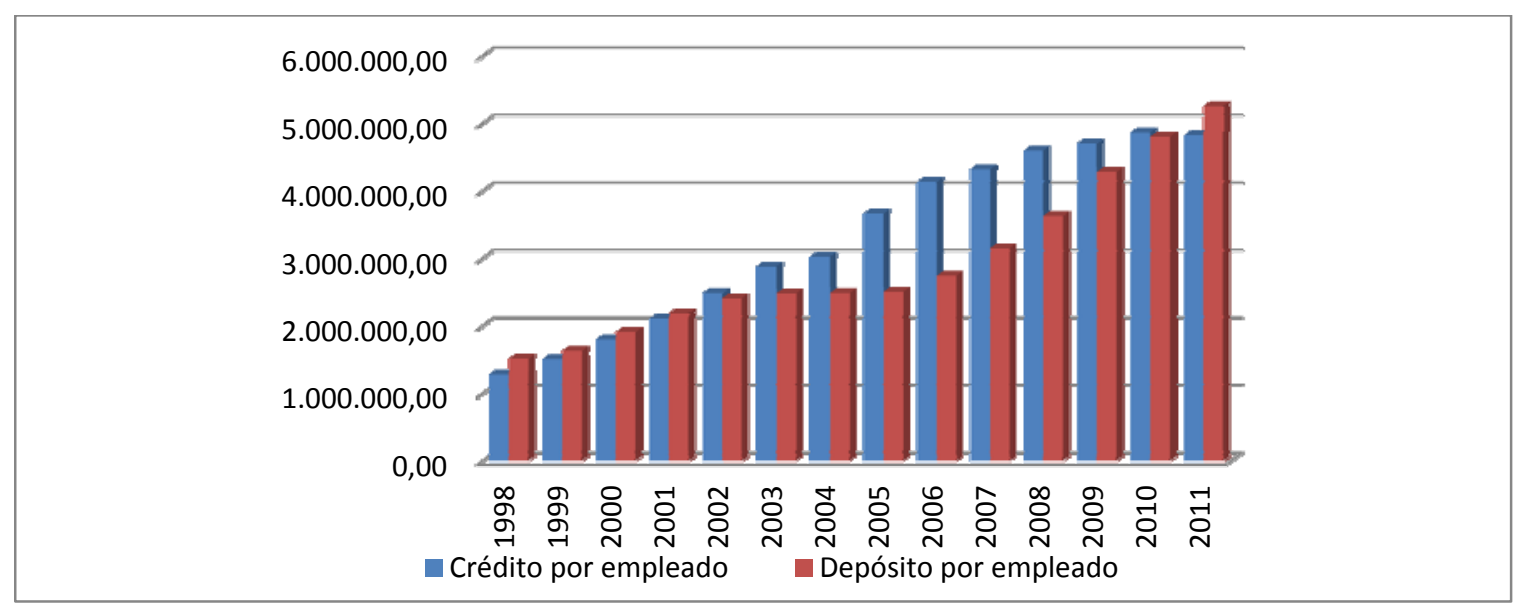

Fuente: Elaboración propia a partir de los datos de la Dirección General de Estadística de la Junta de Castilla y León.

\section{A modo de conclusión: fortalezas, debilidades y estrategias de desamollo}

Del estudio realizado en los apartados anteriores se pueden extraer algunas interesantes conclusiones sobre el sistema financiero en la provincia leonesa, que ponen de manifiesto sus fortalezas y debilidades, y que podemos resumir del siguiente modo:

- Tomando como referencias comparativas la Comunidad Autónoma de Castilla y León y España, se constata un mayor crecimiento en León del número de oficinas que en esos dos ámbitos, propiciada especialmente por el subsector de cajas de ahorros.

- Evolución dispar en el número de oficinas de bancos privados (paulatino descenso) y de cajas de ahorros (fuerte aumento), situándose el punto de inflexión en León en el año 2002 con un llamativo retraso con respecto a Castilla y León (1997) y España (1999).

- Menor cuota de penetración de las cooperativas de crédito en León que en Castilla y León y que en España.

- Fuerte crecimiento de los depósitos, especialmente en las cajas de ahorros que a partir de 1994 son capaces de captar más depósitos que la banca privada invirtiéndose la situación existente hasta entonces, llegándose a una situación en la actualidad en que las cajas captan prácticamente el doble de depósitos que la banca privada. En España el diferencial entre banca privada y cajas es inferior. No obstante, se observa un descenso paulatino en el importe de los depósitos captados a partir de 2008 como consecuencia de la crisis financiera internacional, y a pesar de los esfuerzos realizados por las entidades financieras ofreciendo mejores condiciones a los depositantes.

- Mayor crecimiento de los créditos concedidos por las cajas de ahorros que por la banca privada especialmente en León. No obstante la tasa de penetración en los créditos concedidos de las cajas de ahorros es mayor en León y en Castilla y León que en España donde la banca privada, si bien se mantiene en niveles inferiores a las cajas, aún conserva valores importantes. Descenso significativo también en los créditos concedidos a partir de 2008.

- A partir del 2005 el importe de los créditos concedidos supera al de los depósitos captados, invirtiéndose la situación que se producía hasta entonces. Por agentes a tal situación se llega 
antes en banca privada y cooperativas de crédito que en las cajas.

- Fuerte crecimiento del número de fincas urbanas hipotecadas desde el año 2003 hasta el año 2008 donde se inicia un fuerte descenso. Coincide precisamente con los años de fuerte crecimiento económico de la economía española como consecuencia del tirón producido por la actividad constructora e inmobiliaria formándose la burbuja que ha desencadenado la crisis financiera actual ${ }^{12}$.

- Mayor sensibilidad de las hipotecas sobre viviendas tanto al alza como a la baja. Sigue siendo el grupo cuantitativamente más importante, pero ha ido perdiendo peso paulatinamente respecto a los solares y otras fincas urbanas.

- La importancia relativa del capital hipotecado en viviendas urbanas es menor que la que le corresponde en número.

- Menor grado de bancarización en León que en la Comunidad Autónoma de Castilla y León, manteniéndose en niveles cercanos a 10 oficinas por cada 10.000 habitantes.

- Por agentes, se observa una trayectoria dispar entre banca privada cuyo grado de bancarización desciende a lo largo del periodo y las cajas donde ocurre precisamente lo contrario.

- Hasta el año 1998 los depósitos por habitante se situaban por encima del de los créditos. A partir de esa fecha se produce la situación inversa. Los créditos por habitante en León son muy inferiores a los de la Comunidad Autónoma y España.

- Menor importe de los créditos y depósitos en León por oficina que en España. Además, los créditos por empleado superan a los depósitos más tarde en León que en España.

- En la banca privada los créditos y depósitos y el número de empleados por oficina es mucho menor en León, que en Castilla y León y que en España, y significativamente inferior al de las cajas de ahorros.

\footnotetext{
12 La evolución del sector hipotecario está siendo muy negativa por lo que se impone un tratamiento más selectivo y eficiente de la demanda presente y futura incorporando la variable de riesgo en los procesos de concesión y gestión de las hipotecas lo que probablemente generará un incremento del precio medio en los próximos años (OLIVER WYMAN, 2011).
}

- Mayor descenso en el número de empleados que en el número de oficinas en León a lo largo del periodo considerado.

- A partir del año 2001 es mayor importe de los créditos por empleado que de los depósitos en la banca privada en León. Del 2003 al 2007 crecen mucho más los créditos por empleado que los depósitos. A partir del año 2008 se vuelven a acercar, si bien los créditos se siguen manteniendo por encima de los depósitos por empleado.

Todas estas conclusiones revelan un sistema financiero en León dominado por la actividad de las cajas de ahorros, más centradas en la captación de depósitos de los ahorradores que en las operaciones activas de concesión de créditos, con exceso de capacidad instalada, escaso dinamismo e incapaz de cumplir con las exigencias de una economía moderna. El elevado índice de bancarización, el reducido índice de créditos y depósitos por habitante, por oficina bancaria y por empleado, ponen de manifiesto una baja productividad, una sobredimensión que ha exigido la reestructuración que se está llevando a cabo en la actualidad, especialmente en el subsector de las cajas de ahorros que siguen dominando el panorama en la actividad financiera de la provincia. En esta situación, dadas las consecuencias que para los bancos y cajas de ahorro está teniendo la crisis financiera internacional, solamente queda el recurso a la reordenación del sistema de entidades de crédito tratando de que los entes resultantes presenten indicadores de capital y solvencia más elevados, seleccionen sus inversiones con mayor rigor y profesionalidad y se minimicen las injerencias políticas en el proceso de toma de decisiones. La particular naturaleza jurídica de las cajas, lejos de convertirse en una oportunidad como instrumento activo que contribuyese a dinamizar la actividad productiva de la provincia, ha venido a convertirse en una rémora que ha llegado a comprometer su propio futuro. En estas circunstancias cabe augurar un futuro cercano en el que las cajas de ahorros prácticamente desaparezcan o se conviertan en bancos, la obra social quede reducida a la mínima expresión en manos de fundaciones bancarias sin apenas recursos y las regiones dejen de contar con entidades financieras de vocación regional que contribuyan a dinamizar la actividad económica, social y cultural. El extraordinario papel jugado durante muchísimos años por las cajas de ahorros en todas y cada una 
de las regiones españolas pasará a mejor vida. Los excesos cometidos por los ejecutivos de las cajas de ahorros como consecuencia de la burbuja inmobiliaria y casi siempre por las perniciosas influencias de carácter político ${ }^{13}$, han terminado por liquidar un sector de entidades financieras que tantos servicios ha prestado al desarrollo de nuestro país.

El proceso de reestructuración del sector financiero que aún no ha concluido, debe basarse en estrategias de desarrollo que pongan el énfasis en la profesionalización de la gestión ${ }^{14}$ y en la viabilidad y solvencia de cada entidad, huyendo de cualquier motivación de carácter político. A nuestro juicio, las entidades resultantes de todo este proceso, antiguas cajas de ahorro y hoy en su mayoría bancos, deberán reorientar su modelo de negocio basado en la concesión de créditos hipotecarios hacia la concesión de créditos de carácter productivo (es decir, del crédito a pequeñas y medianas empresas y autónomos), hacia la financiación de la economía real de un determinado ámbito territorial ${ }^{15}$. De este modo se

13 Fue la Ley 31/1985, de 2 de agosto, de regulación de las normas básicas sobre Órganos Rectores de las Cajas de Ahorro (LORCA) la que desencadenó la politización de las cajas, que las ha ido consumiendo poco a poco hasta su práctica desaparición. De la profesionalización de sus órganos rectores se pasó sin solución de continuidad al clientelismo, a la búsqueda de fines electoralistas, a la codicia desmedida, terminando por aniquilar una forma diferente de hacer banca que tantos éxitos había producido.

14 Vicente Cuñat y Luis Garicano, profesores de la London School of Economics y miembros de la Fundación Fedea, han realizado un pormenorizado estudio en el que demuestran que lo que más diferencia a una caja de un banco no es su naturaleza política, como podía parecer, sino la menor profesionalización de sus gestores. Según este estudio, las cajas que tienen un ex político al frente, tienen 0,93 puntos más de morosidad que las que no lo tienen. Si el presidente no tiene estudios de posgrado, 0,98 puntos más. En el caso en que no haya tenido experiencia financiera, 0,93 puntos más. En total, 2,84 puntos más de morosidad para las cajas con gestores sin cualificar, que son los que cumplen las tres condiciones (El País, 31/10/2009).

15 En el Anteproyecto de Ley de Cajas de Ahorros y Fundaciones Bancarias que se está tramitando en la actualidad y que pretende cumplir con los compromisos recogidos en el Memorándum de Entendimiento (MoU) acordado con la Unión Europea como parte del programa de asistencia para la recapitalización del sistema financiero, parece que se quieren corregir parte de los problemas detectados. En este sentido, se pretende que las cajas vuelvan a su modelo tradicional centrado en atender a los pequeños ahorradores y a las pequeñas y medianas empresas de un ámbito territorial determinado, potenciando la profesionalización de los contribuiría decisivamente a la generación de empleo, verdadero talón de Aquiles de la economía española en la actualidad. Así, el sector financiero recuperaría el protagonismo que nunca debió perder en la financiación de las inversiones y mejoraría la reputación tan malparada en los últimos tiempos por estafas tan clamorosas como la de las preferentes. Se debe volver, por tanto, a los límites originales de estas instituciones en lo referente a su actividad bancaria, centrándose en el tramo minorista y en un ámbito regional de actuación ${ }^{16}$.

Mayor incertidumbre recae sobre la Obra Social, pues el traspaso de su negocio financiero a un banco (como han hecho la práctica totalidad de las cajas) la deja reducida a los dividendos que puedan recibir por su participación en él o a los frutos de su propio patrimonio. Habrá que confiar en la buena voluntad de llegar a un acuerdo con los bancos compradores para que sigan financiando la Obra Social por una cuestión de imagen y no perder el arraigo con las zonas de influencia de la caja. Aunque en este tema no podamos ser muy optimistas, el futuro dará o quitará razones.

miembros de los consejos de administración (al menos la mitad de los consejeros han de ser independientes) y reduciendo la participación de las Administraciones Públicas en su gestión (como máximo un 25\% de consejeros).

Para las fundaciones bancarias se establecen rigurosos requisitos de gobierno corporativo, impidiendo que los miembros del patronato de las fundaciones bancarias lo sean asimismo del consejo de administración de la entidad de crédito, limitación que está siendo muy contestada por los altos ejecutivos bancarios que ven peligrar su status. Asimismo, cuando la obra social de la caja se extienda a varias comunidades autónomas, el protectorado corresponderá al Estado, mientras que si su actividad se reduce a una única comunidad, será el gobierno autonómico el que ejercerá el protectorado. Además, las fundaciones bancarias con una participación superior al $50 \%$ o que ostenten posiciones de control en una entidad de crédito estarán obligadas a presentar un plan financiero con estrategias de diversificación de inversiones y de gestión de riesgos y a contar con un fondo de reserva para hacer frente a posibles necesidades de recursos propios de la entidad de crédito participada.

16 En este mismo sentido se manifiesta el Anteproyecto de Ley de Cajas de Ahorros y Fundaciones Bancarias que introduce limitaciones de carácter material, impidiendo que las cajas puedan dedicarse a actividades financieras complejas, de carácter territorial, delimitando el ámbito de actuación de las cajas de ahorros a una Comunidad Autónoma y no más de diez provincias limítrofes, y de dimensión, ya que no podrán tener un activo superior a diez mil millones de euros, o una cuota de depósitos por encima del 35\% de los de la Comunidad Autónoma en la que operen. 


\section{Referencias}

Asociación Española de la Banca. Anuario Estadístico de la Banca en España, años 1999 a 2011. AEB. Recuperado de http://www.aebanca.es/es/Publicaciones/AnuarioEstad\%C3\%ADstico/index.htm (consultas realizadas durante los años 2012 y 2013).

Confederación Española de Cajas de Ahorros: Anuario Estadístico de las Cajas de Ahorro, años 1999 a 2011, CECA. Recuperado de http://www.cajasdeahorros.es/ balance.htm (consultas realizadas durante los años 2012 y 2013).

Coronas Vida, L.J. (2005). Las cajas de ahorro en Castilla y León y su influencia en el desarrollo económico regional. Papeles de Economía Española, no 105 y 106. Recuperado de http://www.funcas.ceca.es/ Publicaciones/InformacionArticulos/Publicaciones.asp?ld=1169 (consultas realizada el 10 de marzo de 2011).

Dirección General de Estadística (2011). Sistema de Información estadística. Junta de Castilla y León. Recuperado de http://www.jcyl.es/web/jcyl/Estadistica/es/Plantilla100/1131978002439 (consultas realizadas durante los años 2012 y 2013).

Fernández Brando, T. et al. (2012). ¿Tiene futuro la red de oficinas bancarias? Proyecto Fin de Máster Executive Máster en Dirección de Entidades Financieras, Febrero 2012.

García Villarejo, A. et al. (Dir.) (2002). Incidencia y participación de las cajas de ahorro en el desarrollo de la actividad productiva de Castilla y León. Informe Técnico encargado por el Consejo Económico y Social de Castilla y León.

Hidalgo Romero, R. (2012). Hacia la desaparición de las cajas de ahorros: la transformación de las cajas de ahorros en fundaciones de carácter especial, Cuatrecasas Gonçalvez Pereira. Recuperado de http://www.cuatrecasas.com/media_repository/docs/esp/hacia_la_desaparicion_de_las_cajas_de_a horros_la_transformacion_de_las_cajas_de_ahorros_en_fundaciones_de_caracter_especial_823.pdf.

ICAL (2013). Las hipotecas sobre viviendas caen en 2012 en Castilla y León un 33,1\% y el capital suscrito baja un 37,2. La Crónica de León, 26 de febrero de 2013.

Instituto Nacional De Estadística (2011): INE base. Recuperado de http://www.ine.es/inebmenu /indice.htm (consultas realizadas durante los años 2012 y 2013).

Lago, M. (2012). Las debilidades del sistema financiero español. Nueva Tribuna.es. 2 de junio de 2012.

Martín Mesa, A. y García Roa, J.: Transformación reciente y situación actual del sector bancario español, Recuperado de http://www.juntadeandalucia.es/export/drupal/economia/TOMO19/BEA19_031.pdf (consulta realizada en febrero de 2013).

Palomo Zurdo, R. y Gutiérrez Fernández, M. (2012). El nuevo mapa bancario en España. Foro - Entidades financieras: Retos de futuro ante un nuevo escenario. Recuperado de http://dictumabogados.com /files/2012/05/Situaci\%C3\%B3n-actual-del-sistema-financiero-Foro-Dictum-EF-25-mayo.pdf (consulta realizada en febrero de 2013).

Sánchez Mato, C. (2012). El sector bancario español. Estimación de necesidades de capital. Informe. Recuperado de http://matoeconomia.blogspot.es/img/necesidades.pdf (consulta realizada en febrero de 2011).

Unión Nacional de Cooperativas de Crédito. Anuario Cajas Rurales, Populares y Profesionales, años 1999 a 2011. Recuperado de http://www.unacc.com/anuario.html (consultas realizadas durante los años 2012 y 2013).

Wyman, O. (2011). El futuro del sector hipotecario en España. El camino hacia el crecimiento sostenible. Informe para la asociación Hipotecaria Española. Recuperado de http://www.gref.org/nuevo/ docs/inf_030911.pdf (consulta realizada en enero de 2013). 


\title{
ANEXO \\ CRÓNICA DE UN TRISTE DESENLACE: DE CÓMO LA CAJA DE AHORROS Y MONTE DE PIEDAD DE LEÓN HA QUEDADO REDUCIDA A LA MÍNIMA EXPRESIÓN
}

\begin{abstract}
El Monte de Piedad y Caja de Ahorros de León nació en el año 1900 como entidad de tipo benéfico con los objetivos de realizar una labor social en la provincia leonesa y conducir el ahorro popular hacia la inversión. En 1948 cambió su nombre por el de Caja de Ahorros y Monte de Piedad de León, lo que venía a certificar el cambio en el énfasis puesto en sus dos líneas de actuación pasando a priorizar la captación del ahorro, sin descuidar, eso sí, su labor asistencial, cultural y social al servicio del desarrollo de la provincia. Durante las décadas del 60, 70 y 80 del pasado siglo, la Caja de Ahorros de León realizó una labor trascendental en la financiación de las inversiones productivas y contribuyó activamente al desarrollo económico y social de León.
\end{abstract}

Después de adquirir en el año 1989 la Caja rural Comarcal del Bierzo, en junio del año 1990 se produjo la fusión de la Caja de Ahorros y Monte de Piedad de León con otras cuatro Cajas de la Comunidad Autónoma, a saber, la Caja de Ahorros Provincial de Zamora, la Caja de Ahorros Popular de Valladolid, la Caja de Ahorros Provincial de Valladolid y la Caja de Ahorros y Monte de Piedad de Palencia. Se formó así la mayor entidad financiera de la región Caja España de Inversiones, Caja de Ahorros y Monte de Piedad, que inició un fuerte proceso de expansión que recibió un rápido impulso mediante la compra en 1994 de más de 100 sucursales del Banco de Fomento. Se rompía así con la tradición de operar exclusivamente al servicio de la región.

En el año 2009, en plena crisis financiera y a instancias del Banco de España, se iniciaron conversaciones con Caja Duero para realizar una fusión que culminaron en junio del año 2010 con la creación de la entidad Caja España de Inversiones, Salamanca y Soria, Caja de Ahorros y Monte de Piedad, con sede social en León y la dirección general en Salamanca.

Acontecimientos posteriores a la fusión, especialmente la publicación el 23/7/2010 por el Comité Supervisor de la Banca Europea (CEBS) de los resultados de los test de estrés de la banca europea en los que Caja España-Caja Duero obtuvo un insuficiente ratio de capital tier 1 del $5,6 \% 17$, lo que exigió una ayuda inicial de 525 millones de euros del Fondo para la Reestructuración Ordenada Bancaria (FROB) y las nuevas exigencias de solvencia impuestas por el Ministerio de Economía aumentando hasta un $10 \%$ los requisitos de capital mínimo para las entidades financieras que no $\operatorname{coticen}^{18}$, pusieron de manifiesto la conveniencia de iniciar nuevas negociaciones con la finalidad de continuar capitalizando a la entidad y de fortalecer su solvencia. Fruto de dichas negociaciones los consejos de Unicaja y Caja España-Caja Duero lograron aprobar en un primer momento la integración de Caja España-Caja Duero y Unicaja, mediante la fórmula de una Sistema Institucional de Protección pasando a constituirse en el tercer grupo de cajas por tamaño. En dicha integración, Unicaja tendría una participación del 70\% y Caja España-Caja Duero del 30\%.

En diciembre de 2012 la fusión llevaba un año de retraso y Unicaja se planteaba adquirir como mínimo un 90\% de la nueva entidad por lo que varió el planteamiento inicial, lanzando el 15 de julio de 2013 una oferta de compra dirigida a los accionistas, preferentistas y titulares de deuda subordinada del banco CEISS.

El 20 de enero de 2014 expiró la oferta de compra, siendo aceptada por el 99\% de los accionistas y por el 61\% de los preferentistas y tenedores de deuda subordinada.

El 12 de marzo de 2014, la Comisión Europea aprobó los cambios en el plan de reestructuración de Banco CEISS. De esta manera, Banco CEISS se beneficiaría de una nueva garantía de un máximo de 241 millones concedida por el FROB para cubrir el coste de litigios con preferentistas que no habían aceptado la oferta de Unicaja Banco.

La aprobación por la Unión Europea conllevará nuevos ajustes que se concretarán la reducción del balance del Banco CEISS en un $28 \%$ entre 2012 y 2016. Además, deberá realizar nuevos esfuerzos de reducción de costes y centrará sus actividades bancarias en la financiación minorista y a las pymes en sus principales regiones de actividad, esto es, Castilla y

17 El límite mínimo establecido era del 6\%.

18 Un $8 \%$ en caso de que coticen. 
León y la provincia de Cáceres. Deberá dejar de conceder financiación a los promotores inmobiliarios y limitará su presencia en actividades mayorista. El 28 de marzo de 2014, Unicaja Banco culminó su compra convirtiendo a Banco CEISS en una filial.

La culminación de este proceso ha supuesto, en cualquier caso, un triste desenlace para una entidad que tanto ha contribuido desde su creación en el año 1900 al desarrollo de la región.

No podríamos entender el desarrollo experimentado en las diferentes comarcas leonesas en el siglo XX, sin hacer referencia al papel desempeñado por la "Caja", tal y como se la conocía coloquialmente en los pueblos. En muchos de ellos, solamente ha existido una sucursal bancaria y el director era considerado con una autoridad a la que se pedía consejo y ayuda. Cómo han cambiado los tiempos, cómo la decisión de incorporar a los órganos rectores a representantes políticos de las Comunidades Autónomas, ha desencadenado un rápido declive de estas instituciones que las ha llevado a su práctica desaparición. Pocas veces los políticos han causado tanto daño al desarrollo de una región. Formar parte del Consejo de Administración de la Caja se convirtió en un objetivo de los políticos de poca monta y con mucha ambición, que no dudaban en utilizar todas sus influencias para conseguir sentarse en los sillones de la sala de juntas situada en la última planta del edificio Botines. La cualificación profesional, la preparación en el ámbito financiero apenas importaba; lo decisivo era constituirse en un fiel defensor de la política del partido, sin cuestionar la conveniencia o no de las operaciones que se sometían a la aprobación de la Junta. Solamente así se entienden algunas decisiones adoptadas en la Caja en los últimos años.

Estamos asistiendo a la práctica desaparición de la obra social de la Caja. Quedará reducida a la mínima expresión, en forma de fundación, sin apenas dotación económica para continuar con su extraordinaria labor de apoyo social, asistencial y cultural. Será una pérdida irreparable para la región y una carga muy pesada para los políticos que han contribuido a ello. De "músculo financiero para la región" tal y como fue bautizada por el más alto representante político de la Comunidad Autónoma en momentos de euforia, a una pequeña fundación con escasa capacidad económica.

En cuanto a la actividad financiera propiamente dicha del Banco CEISS, se ha visto reducida seriamente en la provincia. Ya se ha prescindido de 1.300 empleados y de en torno a 300 sucursales, con una repercusión evidente en la situación económica de la región, y lo que a nuestro juicio es más grave, con los nombramientos realizados recientemente de los nuevos consejeros, la capacidad decisoria escapará definitivamente del ámbito regional. Uno de los pilares sobre los que ha descansado el desarrollo de la provincia se habrá venido abajo irremediablemente. 